\title{
The Anabaena sp. PCC 7120 Exoproteome: Taking a Peek outside the Box
}

\section{Paulo Oliveira ${ }^{1,2, \dagger, *}$, Nuno M. Martins ${ }^{1,2,3, \dagger}$, Marina Santos ${ }^{1,2}$, Narciso A. S. Couto ${ }^{4}$, Phillip C. Wright ${ }^{4}$ and Paula Tamagnini ${ }^{1,2,5}$}

1 Instituto de Investigação e Inovação em Saúde, Universidade do Porto, Porto 4150-180, Portugal; E-Mails: nderesen@ulb.ac.be (N.M.M.); marina.santos@ibmc.up.pt (M.S.); pmtamagn@ibmc.up.pt (P.T.)

2 IBMC-Instituto de Biologia Molecular e Celular, Universidade do Porto, Porto 4150-180, Portugal

3 Laboratoire du Biologie du Noyau, Institut de Biologie \& de Médecine Moléculaire, Université Libre de Bruxelles, Charleroi B-6041, Belgium

4 ChELSI Institute, Chemical and Biological Engineering, University of Sheffield, Sheffield S1 3JD, UK; E-Mails: n.couto@sheffield.ac.uk (N.A.S.C.); p.c.wright@sheffield.ac.uk (P.C.W.)

5 Faculdade de Ciências, Departamento de Biologia, Universidade do Porto, Porto 4169-007, Portugal

$\dagger$ These authors contributed equally to this work.

* Author to whom correspondence should be addressed; E-Mail: paulo.oliveira@ibmc.up.pt; Tel.: +351-22-607-4900; Fax: +351-22-609-9157.

Academic Editors: John C. Meeks and Robert Haselkorn

Received: 29 October 2014 / Accepted: 31 December 2014 / Published: 8 January 2015

Abstract: The interest in examining the subset of proteins present in the extracellular milieu,
the exoproteome, has been growing due to novel insights highlighting their role on
extracellular matrix organization and biofilm formation, but also on homeostasis and
development. The cyanobacterial exoproteome is poorly studied, and the role of
cyanobacterial exoproteins on cell wall biogenesis, morphology and even physiology is
largely unknown. Here, we present a comprehensive examination of the Anabaena sp.
PCC 7120 exoproteome under various growth conditions. Altogether, 139 proteins
belonging to 16 different functional categories have been identified. A large fraction ( $48 \%)$
of the identified proteins is classified as "hypothetical", falls into the "other categories" set
or presents no similarity to other proteins. The evidence presented here shows that Anabaena
sp. PCC 7120 is capable of outer membrane vesicle formation and that these vesicles are 
likely to contribute to the exoproteome profile. Furthermore, the activity of selected exoproteins associated with oxidative stress has been assessed, suggesting their involvement in redox homeostasis mechanisms in the extracellular space. Finally, we discuss our results in light of other cyanobacterial exoproteome studies and focus on the potential of exploring cyanobacteria as cell factories to produce and secrete selected proteins.

Keywords: cyanobacteria; exoprotein; protein secretion; membrane vesicles

\section{Introduction}

Cyanobacteria are prokaryotes that distinctively perform oxygenic photosynthesis. However, the phylum is highly heterogeneous, including strains that are morphologically diverse and metabolically plastic, and some even present the capacity of cellular differentiation. Given their minimal nutritional requirements, cyanobacteria can be found in a wide range of habitats and ecological niches, mainly free-living in aquatic environments, but they can also be found in extreme environments, as well as in symbiotic associations. Their cosmopolitan ecological distribution and their long evolutionary history are strong arguments for placing cyanobacteria among the most successful group of microorganisms.

The total collection of proteins in a cell, tissue or organism, under specific conditions of time, space and environment represents the proteome [1]. Several aspects of the cyanobacterial proteome have been carefully examined over the years. The initial studies aiming at identifying the maximum amount of proteins present in cyanobacteria [2,3] quickly led to more sophisticated analyses of the proteome dynamics in response to changes in environmental cues (e.g., [4-7]), as well as to the result of deleting or over-expressing a particular gene of interest (e.g., [8-10]). Several cyanobacterial strains have been the focus of proteomic studies, including Synechocystis, Anabaena, Nostoc, Cyanothece, Gloeothece and Euhalothece [5,6,11-17]. In addition, the protein composition of various subcellular compartments plus their dynamics in response to environmental and/or genetic changes has also been described, including in the outer-membrane [18,19], periplasm [20], cytoplasmic membrane [21,22], cytosol [23] and thylakoid membrane $[9,24,25]$. Additionally, various reports corroborate that cyanobacteria have the capacity of translocating proteins from the cytoplasm to the extracellular space (e.g., [26-31]). Once translocated across the outer membrane, a protein can remain anchored to the membrane, associate (non)-covalently with outer membrane components, assemble into macromolecular structures on the cell surface or be released into the surrounding environment [32].

The subset of proteins present in the extracellular milieu, the exoproteome, has been poorly studied in cyanobacteria: not only is the number of cyanobacterial strains examined restricted (Synechocystis, Anabaena and Nostoc), but also the growth conditions tested are limited [26,27,30]. Some difficulties arise when studying the exoproteome: many of the exoproteins of interest are transported to the extracellular milieu as the result of active protein secretion via a specific secretion system (secretome). Nevertheless, it may also be possible that cytosolic proteins or even membrane proteins end up accumulating in the extracellular space as the result of cell lysis, being relatively stable to proteolytic cleavage and, thus, contributing to the exoproteome. Thus, as pointed out by Desvaux et al. [32], an exoprotein is not necessarily translocated. Therefore, the major challenge is comprised of distinguishing 
between exoproteins that are secreted from those that accumulate in the extracellular milieu, but that are not actively transported. One strategy to address this challenge is to eliminate the cell's protein secretion systems and evaluate which exoproteins are not transported. Such an analysis has already been adopted for Anabaena sp. PCC 7120 [26]. In that work, Hahn et al. [26] report on the secretome analysis and the involvement of the TolC-like protein, HgdD, a type I secretion system component, on protein secretion.

With the present work, we aim to profile the cyanobacterial exoproteome in the direction of unveiling novel cyanobacterial extracellular processes implicated in cell wall biogenesis, morphology and physiology. Therefore, here, we report on the isolation and identification of the exoproteome of Anabaena sp. PCC 7120 grown in medium with different nitrogen sources. Remarkably, a significant number of proteins were identified, belonging to various functional categories. In the present work, in addition to validating the mass spectrometry protein identifications by assessing some of the respective enzymes' activities, we also analyse the potential of using cyanobacterial protein secretion for biotechnological applications.

\section{Experimental Section}

Organism and growth conditions: The filamentous, heterocyst-forming cyanobacterium Anabaena sp. PCC 7120 (also known as Nostoc sp. PCC 7120) was grown in liquid BG11 [33], BG11 (BG11 medium without nitrate) or $\mathrm{BG}_{1} 1_{0}$ supplemented with $5 \mathrm{mM} \mathrm{NH}_{4} \mathrm{Cl}$ and $10 \mathrm{mM}$ HEPES-NaOH, pH 7.5 $\left(\mathrm{BG} 11_{0}+\mathrm{NH}_{4}^{+}\right)$, under a continuous light regime of $30-40 \mu \mathrm{mol}$ photons $\mathrm{m}^{-2} \mathrm{~s}^{-1}$, at $28{ }^{\circ} \mathrm{C}$. For exoproteome sample collection and concentration, cultures of Anabaena sp. PCC 7120 were inoculated with pre-cultures that had been growing in 100-mL Erlenmeyer flasks containing approximately $50 \mathrm{~mL}$ of culture volume. To minimize filament shearing and mechanical cell lysis, these pre-cultures were maintained either in static conditions or in an orbital shaker under mild shaking conditions (60-80 rpm). Pre-cultures were used as the inoculum when a final chlorophyll $a$ concentration of $5-10 \mu \mathrm{g} \mathrm{mL}^{-1}$ was reached (approximately the same concentration as cultures should reach for exoproteome recovery and concentration; see below). Then, an aliquot of $4 \mathrm{~mL}$ of pre-culture was diluted with fresh growth medium to a final culture volume of $400 \mathrm{~mL}$ (1:100 dilution) in 500-mL glass gas washing bottles. Cultures were grown with aeration with air (flux of approximately $1 \mathrm{~L} \mathrm{~min}^{-1}$ ). In the case of strain BSMPo1, the Anabaena sp. PCC 7120 strain over-expressing hesF under the control of the nirA promoter [34], cultivation was done in BG11 medium supplemented with $30 \mu \mathrm{g} \mathrm{mL} \mathrm{L}^{-1}$ of neomycin.

Exoproteome isolation and analysis: The exoproteome of Anabaena sp. PCC 7120 was isolated as described previously [34]. Briefly, between 100 and $200 \mathrm{~mL}$ of Anabaena sp. PCC 7120 cultures grown in BG11, BG1 $1_{0}$ or BG11 $1_{0}+\mathrm{NH}_{4}{ }^{+}$to a final chlorophyll $a$ concentration of approximately $8-10 \mu \mathrm{g} \mathrm{mL}^{-1}$ were collected by centrifugation $(4000 \times g)$. The supernatants were filtered through $0.2-\mu \mathrm{m}$ pore size filters and further concentrated by centrifugation with Amicon Ultra-15 Centrifugal Filter units (Merck Millipore) with a nominal molecular weight limit of $3 \mathrm{kDa}$. Concentrated exoproteome samples were either used immediately for zymographic and enzyme activity analyses (see below) or saved at $-20{ }^{\circ} \mathrm{C}$ until further analysis. Exoproteome samples were separated by electrophoresis on SDS (sodium dodecyl sulphate)-polyacrylamide gels: in brief, electrophoresis was performed on a vertical mini Protean system (Bio-Rad, Hercules, CA, USA) according to the method of Laemmli [35]. A 10\% gel was prepared, and samples that were mixed with Laemmli sample buffer and heated at $95{ }^{\circ} \mathrm{C}$ for 5 min 
were loaded on the gel. Protein separation was carried out at $20 \mathrm{~mA}$. After protein separation, proteins were visualized using colloidal Coomassie Brilliant Blue G (Sigma-Aldrich, Poole Dorset, UK).

In-gel digestion: In-gel digestion was performed according to Shevchenko et al. [36] with some minor modifications. Briefly, Coomassie Blue-stained bands, observed consistently across at least 3 biological replicates, were excised and cut into cubes $(c a .1 \times 1 \mathrm{~mm})$, which were de-stained by successive washes and incubations (20 min) with a 50:50 (v/v) solution of $100 \mathrm{mM}$ ammonium bicarbonate and acetonitrile. After the reduction and alkylation steps, digestion was performed in the presence of $0.2 \mu \mathrm{g}$ of trypsin (Promega, Fitchburg, WI, USA) for each gel piece. After digestion, peptides were extracted with $50 \mu \mathrm{L}$ of $5 \%(\mathrm{v} / \mathrm{v})$ acetonitrile, $0.1 \%(\mathrm{v} / \mathrm{v})$ formic acid and then with $50 \mu \mathrm{L}$ of $50 \%(\mathrm{v} / \mathrm{v})$ acetonitrile $0.1 \%(\mathrm{v} / \mathrm{v})$ formic acid solution. The combined extracts were concentrated in a vacuum centrifuge at room temperature and stored at $-20^{\circ} \mathrm{C}$ until mass spectrometric analysis.

High-performance liquid chromatography (HPLC) mass spectrometry (MS) analysis: Extracted peptides were reverse-phase separated on an Ultimate 3000 capillary HPLC system (Dionex, Surrey, UK) and MS analysed on an Amazon ion trap mass spectrometer (Bruker, Bremen, Germany) interfaced with and electrospray ion source. On the LC system, a $75 \mu \mathrm{m} \times 15 \mathrm{~cm} \mathrm{C18}$ analytical column (LC Packings) preceded by a C18 trap column (LC Packings) was used to separate peptides at $30{ }^{\circ} \mathrm{C}$ using a flow rate of $300 \mathrm{~nL} \mathrm{~min}^{-1}$. Aqueous buffer (Buffer A, 3\% (v/v) HPLC acetonitrile and 97\% (v/v) HPLC water incorporating 0.1\% (v/v) formic acid) and organic buffer (Buffer B, 97\% (v/v) HPLC acetonitrile and 3\%(v/v) HPLC water incorporating $0.1 \%(\mathrm{v} / \mathrm{v})$ formic acid) were used to perform reverse-phase separation using a 90-min binary gradient started with $0 \%$ Buffer B for 5 min, followed by a linear ramp from $5 \%$ to $40 \%(\mathrm{v} / \mathrm{v})$ Buffer B for $70 \mathrm{~min}$, then an isocratic wash with $90 \%(\mathrm{v} / \mathrm{v})$ Buffer B for $7 \mathrm{~min}$ and column re-equilibration at 5\% (v/v) Buffer B for 8 min. Between every two sample injections, the HPLC ran a 40-min isocratic wash with $100 \%$ Buffer A to act as a blank and purge the system. LC eluate was sprayed on the MS using a capillary voltage of $2700 \mathrm{~V}$, an end plate offset of $500 \mathrm{~V}$, a dry gas temperature of $180^{\circ} \mathrm{C}$ and a dry gas of $6 \mathrm{~L} \mathrm{~min}^{-1}$. The MS was set to detect positive ions using the standard enhanced mode with an $\mathrm{m} / \mathrm{z}$ range of 200-2000. Ions were accumulated in the trap until the ion charge count (ICC) reached 20,000 with a maximum accumulation time of $200 \mathrm{~ms}$. Peptide sequence information was inferred by collision-induced dissociation (CID) tandem mass spectrometry (MS/MS) experiments in a data-dependent acquisition fashion by selecting auto MS(n), where the top four most intense peaks were chosen for dissociation with a total ion count (TIC) absolute threshold of 25,000 and a relative threshold of $5 \%$ of the base peak.

MS/MS database search: After acquisition, raw data were converted into a mascot generic file (mgf) using DataAnalysis ${ }^{\mathrm{TM}}$ software, Version 4.2 (Bruker, Bremen, Germany). These peak lists containing the smoothed and centroided $\mathrm{m} / \mathrm{z}$ and signal intensities were used for peptide identification using the EasyProt search algorithm [37] (developed between the Biomedical Proteomics Research Group of the Human Protein Science department at the University of Geneva, the Swiss Center for Applied Human Toxicology and the Swiss Institute of Bioinformatics) and the Anabaena sp. PCC 7120 protein database available at and downloaded from UniProt (http://www.uniprot.org/; accessed in July 2013). On EasyProt, trypsin was set as the enzyme, allowing for two missed cleavages; carbamidomethyl cysteine was considered as a fixed modification and oxidation of methionine as variable modification. The peptide tolerance and MS/MS tolerance were set to 0.6 Da. Data files containing CID were searched using the ESI-trap. Data quality was filtered, allowing only peptide identification with a Z-score $>5$ and a 
minimum length of 6 amino acids. To determine which proteins were present in the sample, a false discovery rate of no more than $1 \%$ was chosen, calculated using a reverse target-decoy [38] automatically generated by EasyProt. A further stringency of a minimum of two peptides identified per protein was applied. Subcellular localization prediction of proteins identified in the different exoproteomes was carried out using the online tool, PSORTb version 3.0 [39].

Superoxide dismutase (SOD) zymography and catalase activity analyses: Total protein extractions from Anabaena sp. PCC 7120 were performed using an extraction buffer containing either $50 \mathrm{mM}$ Tris-HCl pH 7.5, 1 mM EDTA, 2 mM DTT, 10\% glycerol and supplemented with a protease inhibitor cocktail (cOmplete Mini, EDTA-free, Roche, Basel, Switzerland) [40] for SOD measurements or $50 \mathrm{mM}$ potassium phosphate $\mathrm{pH} 7.0$ for catalase activity determination. In both cases, cells were lysed by sonication (Branson sonifier, Genève, Switzerland). Superoxide dismutase activity was assessed by in-gel zymography in the following way: the protein content present in approximately $15-20 \mathrm{~mL}$ of each cell-free growth medium (of cultures grown to a chlorophyll $a$ concentration of $7-10 \mu \mathrm{g} \mathrm{mL}^{-1}$ ) and $100-550 \mu \mathrm{g}$ of total protein were separated by electrophoresis on $10 \%(\mathrm{w} / \mathrm{v})$ native-acrylamide gels. After electrophoresis, the gel was incubated $20 \mathrm{~min}$ in a $2.5 \mathrm{mM}$ nitroblue-tetrazolium solution, followed by a 15 -min incubation in SOD developing solution $(36 \mathrm{mM}$ potassium phosphate buffer, $\mathrm{pH} 7.8$; $28 \mathrm{mM}$ tetramethylethylenediamine and $86 \mu \mathrm{M}$ riboflavin; for inhibition of the Fe containing SOD, $5 \mathrm{mM} \mathrm{H}_{2} \mathrm{O}_{2}$ was added to the SOD developing solution according to [41]). The gel was then exposed to a 60 -W light source until full development. For catalase activity assessment, global catalase activity was determined following the $\mathrm{H}_{2} \mathrm{O}_{2}$ dissociation by measuring absorbance at $240 \mathrm{~nm}$. In brief, between 300 and $450 \mu \mathrm{g}$ of total protein or the protein content present in approximately $10-20 \mathrm{~mL}$ of culture were mixed in a quartz cuvette with $50 \mathrm{mM}$ potassium phosphate buffer $(\mathrm{pH} 7.0)$ and $\mathrm{H}_{2} \mathrm{O}_{2}$ to a final concentration of $20 \mathrm{mM}$. The reaction was then followed spectrophotometrically at $240 \mathrm{~nm}$ for $3 \mathrm{~min}$. Catalase activity is expressed as units per mg of total protein (when cell-free extracts were used) or units per $\mu \mathrm{g}$ of chlorophyll $a$ (in the case of exoproteome samples), defining a unit as the amount of enzyme that catalyses the dissociation of $1 \mu \mathrm{mol}$ of $\mathrm{H}_{2} \mathrm{O}_{2}$ per minute at $\mathrm{pH} 7.0$ at room temperature. For both SOD and catalase activity determinations, protein samples obtained from at least three biological replicates were used.

Determination of reactive oxygen species (ROS): To determine the total amount of ROS found in BG11, BG1 $1_{0}$ and BG1 $1_{0}+\mathrm{NH}_{4}{ }^{+}$, the general oxidative stress indicator 2', 7'-dichlorodihydrofluorescein diacetate ( $\left.\mathrm{H}_{2} \mathrm{DCF}-\mathrm{DA}\right)$ (Life Technologies, Carlsbad, CA, USA) was used. When used in intact cells, intracellular esterases cleave the ester groups and remove the acetate, readily converting the non-fluorescent molecule $\mathrm{H}_{2}$ DCF-DA to carboxy-dichlorofluorescein (DCF), a green-fluorescent form of the molecule upon oxidation by the activity of ROS. To obtain DCF in vitro, $\mathrm{H}_{2} \mathrm{DCF}-\mathrm{DA}$ was hydrolysed with $0.01 \mathrm{M} \mathrm{NaOH}$ for $30 \mathrm{~min}$ at $37{ }^{\circ} \mathrm{C}$ in the dark [42]. Autoclaved BG11, BG1 $1_{0}$ and BG1 $1_{0}+\mathrm{NH}_{4}$ media were kept sterile in the same conditions as cultures of Anabaena sp. PCC 7120, i.e., in glass gas washing bottles with aeration, at $28^{\circ} \mathrm{C}$, under a continuous light regime of 30-40 $\mu \mathrm{mol}$ photons $\mathrm{m}^{-2} \mathrm{~s}^{-1}$. Samples of each sterile medium were collected and loaded on 96-well microtiter plates and mixed with DCF to a final concentration of $5 \mu \mathrm{M}$. ROS levels of medium samples supplemented with $0.5 \mathrm{mM} \mathrm{H}_{2} \mathrm{O}_{2}$ were also determined by DCF fluorescence in the same microtiter plate. After the addition of DCF, plates were incubated $1 \mathrm{~h}$ at $30{ }^{\circ} \mathrm{C}$ in the dark, followed by determination of DCF fluorescence at $528 / 20 \mathrm{~nm}$ after excitation at $485 / 20 \mathrm{~nm}$ on a Synergy 2 multi-mode microplate reader (BioTek, Winooski, VT, USA). 
Negative-staining transmission electron microscopy: For negative staining transmission electron microscopy, $10 \mu \mathrm{L}$ of concentrated exoproteome samples were mounted on Formvar/carbon film-coated mesh nickel grids (Electron Microscopy Sciences, Hatfield, PA, USA) and left standing for 2 min. The liquid in excess was removed with filter paper, and $10 \mu \mathrm{L}$ of $1 \%$ uranyl acetate were added on to the grids and left standing for $10 \mathrm{~s}$, after which, liquid in excess was removed with filter paper. Visualization was carried out on a Jeol JEM-1400 at $80 \mathrm{kV}$.

\section{Results and Discussion}

\subsection{The Exoproteome of Anabaena sp. PCC 7120}

Currently, in our group, we are identifying the exoproteome of various cyanobacterial strains, aiming at understanding the role of exoproteins on the cell structure and physiology. Briefly, the cells were grown under different conditions; samples were taken periodically during the culture growth and the growth medium was separated from the cells by mild centrifugation and filtration. The resulting cell-free medium was then concentrated by ultrafiltration (for details, see the Experimental Section). The exoproteome of Anabaena sp. PCC 7120 grown in medium with different combined nitrogen sources (nitrate or ammonia) or in nitrogen-fixing conditions separated by SDS-polyacrylamide gel electrophoresis is presented in Figure 1. The total amount of proteins accumulating in the growth medium, regardless of the cultivating conditions, is substantial, supporting the notion that Anabaena sp. PCC 7120 can indeed export and release proteins to the extracellular space with a specific function in that particular environment. This hypothesis gets further support from the observation that the exoproteome profiles in the three conditions tested present differential compositions, indicating that some proteins are specifically expressed in a given condition and could be exported to the extracellular milieu to fulfil a particular task.

When studying the exoproteome of a microorganism, the possible contribution of cell lysis or leakage to the whole exoproteome is an issue that deserves careful consideration. In the present work, this question was addressed experimentally, trying to minimize its contribution. For that purpose, growth medium from cultures of Anabaena sp. PCC 7120 cultivated in the three different growth conditions described was periodically sampled and the respective exoproteomes analysed (data not shown). This was done in order to evaluate whether some exoproteins could accumulate differentially in the extracellular space with respect to particular growth phases, but also to assess the contribution of cell lysis during the cultivation period (we hypothesized that as cultures get older, more cytoplasmic content ends up accumulating in the medium as a result of cell death and/or cumulative cell lysis). Hence, cultures that had reached a chlorophyll $a$ concentration of approximately $8-10 \mu \mathrm{g} \mathrm{mL}{ }^{-1}$ were then used for exoproteome analyses. Moreover, cells of Anabaena sp. PCC 7120 were also cultivated in different types of systems. Initially, cultivation was carried out in glass gas washing bottles with continuous aeration (see Experimental Section). However, since culture aeration may result in filament shearing and ultimately lead to mechanical cell lysis, we also grew Anabaena sp. PCC 7120 cultures in milder conditions, namely in 1-L Erlenmeyer flasks (with $300 \mathrm{~mL}$ of culture volume) in an orbital shaker with gentle shaking (100 rpm). However, no significant differences could be observed in the overall exoproteome composition between the various conditions as assessed by observation of colloidal Coomassie Brilliant 
Blue G-stained SDS-polyacrylamide gels (data not shown). Thus, cultivation in glass gas washing bottles was preferred due to the higher growth rates observed for Anabaena sp. PCC 7120.

In order to identify the proteins in the Anabaena sp. PCC 7120 exoproteomes, we started by performing mass spectrometric analyses directly on concentrated culture supernatants. However, given the high biomolecular heterogeneity of the cyanobacterial growth medium after cultivation, which is composed not only of proteins, but also of, e.g., extracellular polysaccharides $[43,44]$, this approach resulted in poor protein identification. In fact, most of the results obtained could not be matched to any peptide. Thus, we decided to separate the various components of the concentrated supernatants by SDS-polyacrylamide gel electrophoresis and to proceed for protein identification by selecting Coomassie Blue-stained bands and/or gel portions that had been observed consistently across at least three biological replicates (see Figure 1).

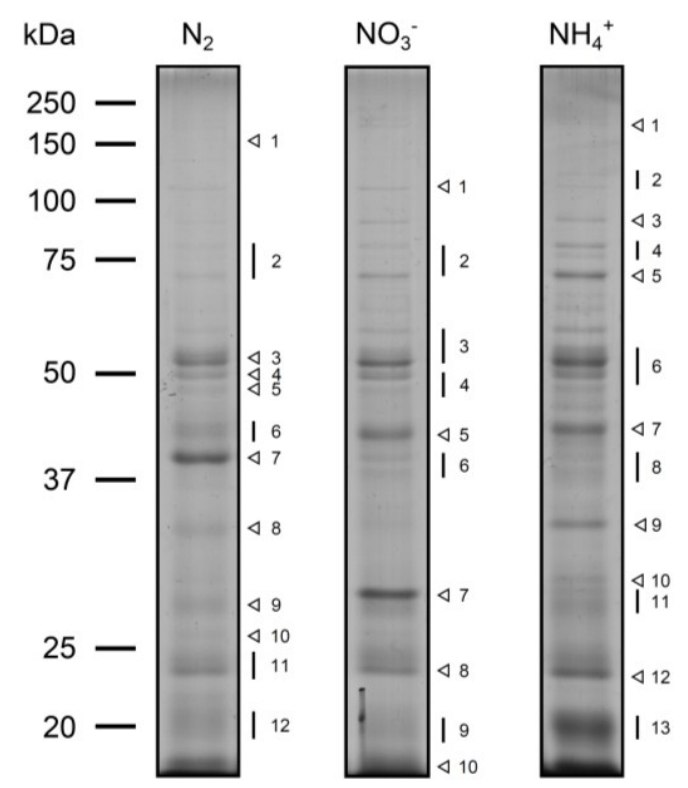

Figure 1. Exoproteome profiles of Anabaena sp. PCC 7120 cultivated under various growth conditions. Wild-type cells of Anabaena sp. PCC 7120 were grown in nitrogen-fixing conditions $\left(\mathrm{N}_{2}\right)$ or in medium supplemented with nitrate $\left(\mathrm{NO}_{3}{ }^{-}\right)$or ammonia $\left(\mathrm{NH}_{4}{ }^{+}\right)$. The protein content present in $5 \mathrm{~mL}$ of each cell-free growth medium was separated by SDS-polyacrylamide gel electrophoresis and the exoproteomes visualized by Coomassie Blue staining. Bands and gel areas selected for in-gel trypsin digestion and further protein identification by mass spectrometry are highlighted on the right of each panel by arrowheads and lines, respectively. Proteins identified in each band and the gel portion are listed in the Supplementary Information. The molecular masses of the Precision Plus Protein All Blue standard (Bio-Rad, Hercules, CA, USA) are indicated on the left.

Proteins identified in the extracellular milieu of Anabaena sp. PCC 7120 cells grown in nitrogen-fixing conditions or in medium supplemented with nitrate or ammonia are listed in Table 1 (for details, see the Supporting Information). Altogether, peptides from 139 different proteins, belonging to 16 functional categories, were identified. 
Table 1. List of proteins identified in the exoproteome of Anabaena sp. PCC 7120 grown in nitrogen-fixing conditions or in media supplemented with nitrate or ammonia.

\begin{tabular}{|c|c|c|c|c|}
\hline Cyanobase $^{\mathrm{a}}$ & Annotation $^{\mathrm{b}}$ & Growth Condition $^{\mathrm{c}}$ & Functional Category $^{\mathrm{d}}$ & Previously Identified in ${ }^{\mathrm{e}}$ \\
\hline All0004 & ATP synthase gamma chain & $\mathrm{NH}_{4}^{+}$ & Photosynthesis and respiration & - \\
\hline Al10005 & ATP synthase subunit alpha & $\mathrm{N}_{2}, \mathrm{NH}_{4}^{+}$ & Photosynthesis and respiration & Anabaena \\
\hline Al10167 & Maltooligosyltrehalose synthase & $\mathrm{NH}_{4}^{+}$ & Other categories & - \\
\hline Al10168 & Alpha-amylase & $\mathrm{NO}_{3}^{-}$ & Other categories & - \\
\hline Al10207 & All0207 protein & $\mathrm{NO}_{3}^{-}$ & Conserved hypothetical protein & - \\
\hline Al10259 & Cytochrome c-550 & $\mathrm{NH}_{4}^{+}$ & Photosynthesis and respiration & - \\
\hline Al10268 & All0268 protein & $\mathrm{NH}_{4}^{+}$ & Conserved hypothetical protein & - \\
\hline Al10275 & Glycerophosphoryl diester phosphodiesterase & $\mathrm{NO}_{3}^{-}, \mathrm{NH}_{4}^{+}$ & Other categories & Anabaena \\
\hline Al10458 & $\begin{array}{l}\text { Uncharacterized low temperature-induced } \\
\text { protein all0458 }\end{array}$ & $\mathrm{NH}_{4}^{+}$ & Conserved hypothetical protein & Anabaena \\
\hline All0875 & Al10875 protein & $\mathrm{N}_{2}, \mathrm{NH}_{4}^{+}$ & Other categories & Anabaena \\
\hline All1220 & All1220 protein & $\mathrm{NH}_{4}^{+}$ & Conserved hypothetical protein & - \\
\hline All1342 & All1342 protein & $\mathrm{NO}_{3}^{-}$ & No similarity & - \\
\hline All1380 & All1380 protein & $\mathrm{NO}_{3}{ }^{-}, \mathrm{NH}_{4}^{+}$ & No similarity & - \\
\hline All1683 & Phosphoserine aminotransferase & $\mathrm{N}_{2}$ & Amino acid biosynthesis & - \\
\hline All1750 & All1750 protein & $\mathrm{NO}_{3}^{-}$ & No similarity & - \\
\hline All1951 & Substrate-binding protein of $\mathrm{ABC}$ transporter & $\mathrm{N}_{2}, \mathrm{NO}_{3}^{-}, \mathrm{NH}_{4}^{+}$ & Transport and binding proteins & - \\
\hline All2105 & FMN-dependent NADH-azoreductase & $\mathrm{NH}_{4}^{+}$ & $\begin{array}{l}\text { Fatty acid, phospholipid } \\
\text { and sterol metabolism }\end{array}$ & Anabaena \\
\hline Al12108 & All2108 protein & $\mathrm{NO}_{3}^{-}$ & Conserved hypothetical protein & - \\
\hline All2315 & Ketol-acid reductoisomerase & $\mathrm{NO}_{3}^{-}, \mathrm{NH}_{4}^{+}$ & Amino acid biosynthesis & - \\
\hline Al12316 & Aldo/keto reductase & $\mathrm{NH}_{4}^{+}$ & Other categories & - \\
\hline Al12375 & All2375 protein & $\mathrm{NH}_{4}^{+}$ & Transport and binding proteins & - \\
\hline All2425 & All2425 protein & $\mathrm{NH}_{4}^{+}$ & No similarity & - \\
\hline All2453 & Cytochrome b6-f complex iron-sulphur subunit 1 & $\mathrm{NH}_{4}^{+}$ & Photosynthesis and respiration & - \\
\hline All2498 & $\mathrm{N}$-acetyl-gamma-glutamyl-phosphate reductase 2 & $\mathrm{NH}_{4}^{+}$ & Transport and binding proteins & - \\
\hline
\end{tabular}


Table 1. Cont.

\begin{tabular}{|c|c|c|c|c|}
\hline Cyanobase $^{\mathrm{a}}$ & Annotation $^{\mathrm{b}}$ & $\begin{array}{c}\text { Growth } \\
\text { Condition }^{\mathrm{c}} \\
\end{array}$ & Functional Category $^{\mathrm{d}}$ & Previously Identified in ${ }^{\mathrm{e}}$ \\
\hline All2533 & Prolyl endopeptidase & $\mathrm{N}_{2}, \mathrm{NH}_{4}^{+}$ & Translation & - \\
\hline Al12563 & Transaldolase & $\mathrm{N}_{2}, \mathrm{NO}_{3}^{-}, \mathrm{NH}_{4}^{+}$ & Energy metabolism & Anabaena \\
\hline Al12567 & Probable phosphoketolase 2 & $\mathrm{NH}_{4}^{+}$ & Conserved hypothetical protein & - \\
\hline All2655 & All2655 protein & $\mathrm{NH}_{4}^{+}$ & No similarity & - \\
\hline All2843 & Alkaline phosphatase & $\mathrm{NO}_{3}^{-}, \mathrm{NH}_{4}^{+}$ & Other categories & N. commune \\
\hline Al13149 & All3149 protein & $\mathrm{NO}_{3}^{-}, \mathrm{NH}_{4}^{+}$ & Conserved hypothetical protein & - \\
\hline Al13325 & All3325 protein & $\mathrm{NH}_{4}^{+}$ & Conserved hypothetical protein & - \\
\hline Al13538 & Enolase & $\mathrm{N}_{2}, \mathrm{NH}_{4}^{+}$ & Energy metabolism & N. punctiforme, Anabaena \\
\hline Al13556 & Succinate-semialdehyde dehydrogenase & $\mathrm{N}_{2}, \mathrm{NO}_{3}^{-}$ & Energy metabolism & - \\
\hline Al13643 & All3643 protein & $\mathrm{NH}_{4}^{+}$ & No similarity & - \\
\hline All3653 & Allophycocyanin subunit alpha-B & $\mathrm{NH}_{4}^{+}$ & Photosynthesis and respiration & - \\
\hline All3791 & Ribonuclease D & $\mathrm{NH}_{4}^{+}$ & Transcription & - \\
\hline All3797 & Beta-Ig-H3/fasciclin (Fragment) & $\mathrm{N}_{2}, \mathrm{NH}_{4}^{+}$ & Conserved hypothetical protein & Anabaena \\
\hline All3909 & Uroporphyrinogen decarboxylase & $\mathrm{NO}_{3}{ }^{-}, \mathrm{NH}_{4}{ }^{+}$ & $\begin{array}{l}\text { Biosynthesis of cofactors, } \\
\text { prosthetic groups, and carriers }\end{array}$ & - \\
\hline All3964 & Phosphoglucomutase/phosphomannomutase & $\mathrm{N}_{2}, \mathrm{NO}_{3}^{-}, \mathrm{NH}_{4}^{+}$ & Central intermediary metabolism & Anabaena \\
\hline All3984 & All3984 protein & $\mathrm{N}_{2}$ & Conserved hypothetical protein & N. punctiforme \\
\hline All4038 & All4038 protein & $\mathrm{NH}_{4}^{+}$ & No similarity & - \\
\hline All4050 & All4050 protein & $\mathrm{NH}_{4}^{+}$ & Conserved hypothetical protein & Anabaena \\
\hline All4121 & Ferredoxin--NADP reductase & $\mathrm{N}_{2}, \mathrm{NO}_{3}^{-}, \mathrm{NH}_{4}^{+}$ & Photosynthesis and respiration & Anabaena \\
\hline All4131 & Phosphoglycerate kinase & $\mathrm{N}_{2}, \mathrm{NO}_{3}{ }^{-}, \mathrm{NH}_{4}^{+}$ & Regulatory functions & $\begin{array}{c}\text { N. commune, } \\
\text { N. punctiforme, Anabaena }\end{array}$ \\
\hline All4145 & All4145 protein & $\mathrm{NH}_{4}^{+}$ & Other categories & - \\
\hline All4191 & DNA-directed RNA polymerase subunit alpha & $\mathrm{NH}_{4}^{+}$ & Transcription & - \\
\hline All4214 & 50S ribosomal protein L4 & $\mathrm{NH}_{4}^{+}$ & Translation & - \\
\hline All4287 & Peptidyl-prolyl cis-trans isomerase B & $\mathrm{NH}_{4}^{+}$ & Translation & N. punctiforme \\
\hline
\end{tabular}


Table 1. Cont.

\begin{tabular}{|c|c|c|c|c|}
\hline Cyanobase $^{\mathrm{a}}$ & Annotation $^{\mathrm{b}}$ & Growth Condition ${ }^{\mathrm{c}}$ & Functional Category $^{\mathrm{d}}$ & Previously Identified in ${ }^{\mathrm{e}}$ \\
\hline All4388 & All4388 protein & $\mathrm{N}_{2}$ & Conserved hypothetical protein & - \\
\hline Al14464 & Phosphoadenosine phosphosulfate reductase & $\mathrm{NO}_{3}^{-}, \mathrm{NH}_{4}^{+}$ & Amino acid biosynthesis & - \\
\hline Al14499 & All4499 protein & $\mathrm{N}_{2}, \mathrm{NO}_{3}^{-}$ & Conserved hypothetical protein & - \\
\hline Al14539 & L-sorbosone dehydrogenase & $\mathrm{N}_{2}, \mathrm{NO}_{3}^{-}, \mathrm{NH}_{4}^{+}$ & Other categories & N. punctiforme \\
\hline Al14563 & Fructose-bisphosphate aldolase & $\mathrm{NH}_{4}^{+}$ & Other categories & - \\
\hline All4575 & $\begin{array}{l}\text { Phosphate-binding periplasmic protein of } \\
\text { phosphate } A B C \text { transporter }\end{array}$ & $\mathrm{N}_{2}, \mathrm{NO}_{3}^{-}, \mathrm{NH}_{4}^{+}$ & Transport and binding proteins & - \\
\hline All4749 & All4749 protein & $\mathrm{NO}_{3}^{-}, \mathrm{NH}_{4}^{+}$ & Conserved hypothetical protein & - \\
\hline Al14906 & Phosphoglycerate mutase & $\mathrm{N}_{2}$ & Energy metabolism & - \\
\hline All4968 & Glutathione reductase & $\mathrm{N}_{2}, \mathrm{NO}_{3}^{-}$ & $\begin{array}{l}\text { Biosynthesis of cofactors, } \\
\text { prosthetic groups, and carriers }\end{array}$ & Anabaena \\
\hline All4985 & Sucrose synthase & $\mathrm{NH}_{4}^{+}$ & Energy metabolism & - \\
\hline Al15039 & ATP synthase subunit beta & $\mathrm{N}_{2}, \mathrm{NO}_{3}^{-}, \mathrm{NH}_{4}^{+}$ & Photosynthesis and respiration & Anabaena \\
\hline A115062 & Glyceraldehyde-3-phosphate dehydrogenase 2 & $\mathrm{~N}_{2}, \mathrm{NH}_{4}^{+}$ & Photosynthesis and respiration & - \\
\hline Al17614 & Al17614 protein & $\mathrm{N}_{2}, \mathrm{NO}_{3}^{-}$ & Conserved hypothetical protein & - \\
\hline Al17633 & All7633 protein & $\mathrm{NO}_{3}^{-}, \mathrm{NH}_{4}^{+}$ & Conserved hypothetical protein & - \\
\hline Alr0020 & Phycobiliprotein ApcE & $\mathrm{NH}_{4}^{+}$ & Photosynthesis and respiration & - \\
\hline Alr0021 & Allophycocyanin subunit alpha 1 & $\mathrm{~N}_{2}, \mathrm{NO}_{3}^{-}, \mathrm{NH}_{4}^{+}$ & Photosynthesis and respiration & N. punctiforme, Anabaena \\
\hline Alr0022 & Allophycocyanin subunit beta & $\mathrm{N}_{2}, \mathrm{NO}_{3}^{-}, \mathrm{NH}_{4}^{+}$ & Photosynthesis and respiration & Anabaena \\
\hline Alr0051 & IMP dehydrogenase & $\mathrm{NO}_{3}^{-}$ & $\begin{array}{l}\text { Purines, pyrimidines, nucleosides, } \\
\text { and nucleotides }\end{array}$ & - \\
\hline Alr0069 & Ribonuclease PH & $\mathrm{NH}_{4}^{+}$ & Transcription & - \\
\hline Alr0132 & Alr0132 protein & $\mathrm{NO}_{3}^{-}, \mathrm{NH}_{4}^{+}$ & Conserved hypothetical protein & Anabaena \\
\hline Alr0140 & $\begin{array}{l}\text { Periplasmic oligopeptide-binding protein of } \\
\text { oligopeptide ABC transporter }\end{array}$ & $\mathrm{N}_{2}, \mathrm{NO}_{3}^{-}, \mathrm{NH}_{4}^{+}$ & Transport and binding proteins & - \\
\hline Alr0169 & Cyclomaltodextrin glucanotransferase & $\mathrm{NH}_{4}^{+}$ & Other categories & - \\
\hline
\end{tabular}


Table 1. Cont.

\begin{tabular}{|c|c|c|c|c|}
\hline $\begin{array}{c}\text { Cyanobase } \\
\text { a }\end{array}$ & Annotation $^{\mathrm{b}}$ & Growth Condition $^{\mathrm{c}}$ & Functional Category $^{\mathrm{d}}$ & Previously Identified in ${ }^{\mathrm{e}}$ \\
\hline Alr0237 & Probable cytosol aminopeptidase & $\mathrm{N}_{2}, \mathrm{NH}_{4}^{+}$ & Translation & - \\
\hline Alr0267 & Alr0267 protein & $\mathrm{N}_{2}, \mathrm{NO}_{3}^{-}$ & No similarity & N. punctiforme, Anabaeno \\
\hline Alr0474 & Alr0474 protein & $\mathrm{NO}_{3}^{-}, \mathrm{NH}_{4}^{+}$ & No similarity & - \\
\hline Alr0523 & Phycoerythrocyanin subunit beta & $\mathrm{N}_{2}, \mathrm{NO}_{3}^{-}, \mathrm{NH}_{4}^{+}$ & Photosynthesis and respiration & N. commune \\
\hline Alr0525 & $\begin{array}{l}\text { Phycobilisome } 34.5 \mathrm{kDa} \text { linker polypeptide, } \\
\text { phycoerythrocyanin-associated, rod }\end{array}$ & $\mathrm{NO}_{3}^{-}$ & Photosynthesis and respiration & N. commune \\
\hline Alr0528 & C-phycocyanin subunit beta & $\mathrm{N}_{2}, \mathrm{NO}_{3}^{-}, \mathrm{NH}_{4}^{+}$ & Photosynthesis and respiration & N. punctiforme, Anabaenc \\
\hline Alr0529 & C-phycocyanin alpha chain & $\mathrm{N}_{2}, \mathrm{NO}_{3}^{-}, \mathrm{NH}_{4}^{+}$ & Photosynthesis and respiration & N. punctiforme, Anabaenc \\
\hline Alr0530 & $\begin{array}{l}\text { Phycobilisome } 32.1 \mathrm{kDa} \text { linker polypeptide, } \\
\text { phycocyanin-associated, rod }\end{array}$ & $\mathrm{N}_{2}, \mathrm{NO}_{3}{ }^{-}, \mathrm{NH}_{4}{ }^{+}$ & Photosynthesis and respiration & N. commune \\
\hline Alr0534 & Phycobilisome rod-core linker polypeptide CpcG1 & $\mathrm{NO}_{3}^{-}, \mathrm{NH}_{4}^{+}$ & Photosynthesis and respiration & N. commune \\
\hline Alr0608 & Nitrate transport protein NrtA & $\mathrm{N}_{2}, \mathrm{NO}_{3}^{-}, \mathrm{NH}_{4}^{+}$ & Amino acid biosynthesis & Anabaena \\
\hline Alr0782 & Ribulose-phosphate 3-epimerase & $\mathrm{NH}_{4}^{+}$ & Central intermediary metabolism & N. commune, Anabaena \\
\hline Alr0834 & Porin major outer membrane protein & $\mathrm{N}_{2}, \mathrm{NO}_{3}^{-}$ & Cell envelope & - \\
\hline Alr0880 & Oligopeptidase A & $\mathrm{NH}_{4}^{+}$ & Translation & - \\
\hline Alr0996 & Protease & $\mathrm{N}_{2}$ & Translation & - \\
\hline Alr1004 & Alanine--glyoxylate aminotransferase & $\mathrm{N}_{2}$ & Amino acid biosynthesis & - \\
\hline Alr1050 & Glucose-6-phosphate isomerase & $\mathrm{N}_{2}, \mathrm{NO}_{3}^{-}, \mathrm{NH}_{4}^{+}$ & Energy metabolism & Anabaena \\
\hline Alr1080 & Acetylornithine aminotransferase & $\mathrm{N}_{2}$ & Amino acid biosynthesis & - \\
\hline Alr1299 & Phosphoribosylglycinamide formyltransferase 2 & $\mathrm{~N}_{2}$ & $\begin{array}{l}\text { Purines, pyrimidines, nucleosides, } \\
\text { and nucleotides }\end{array}$ & - \\
\hline Alr1310 & Alr1310 protein & $\mathrm{NH}_{4}^{+}$ & Conserved hypothetical protein & - \\
\hline Alr1313 & 3-isopropylmalate dehydrogenase & $\mathrm{NH}_{4}^{+}$ & Amino acid biosynthesis & - \\
\hline Alr1329 & Alr1329 protein & $\mathrm{N}_{2}$ & No similarity & - \\
\hline Alr1348 & Ferredoxin-sulphite reductase & $\mathrm{NO}_{3}^{-}$ & Other categories & - \\
\hline Alr1362 & Alr1362 protein & $\mathrm{NO}_{3}^{-}$ & Other categories & - \\
\hline
\end{tabular}


Table 1. Cont.

\begin{tabular}{|c|c|c|c|c|}
\hline Cyanobase $^{\mathrm{a}}$ & Annotation $^{\mathrm{b}}$ & Growth Condition $^{\mathrm{c}}$ & Functional Category $^{\mathrm{d}}$ & Previously Identified in ${ }^{\mathrm{e}}$ \\
\hline Alr1364 & Alr1364 protein & $\mathrm{NH}_{4}^{+}$ & Conserved hypothetical protein & - \\
\hline Alr1381 & Calcium-dependent protease & $\mathrm{NO}_{3}^{-}$ & Translation & - \\
\hline Alr1520 & Alr1520 protein & $\mathrm{NO}_{3}^{-}$ & Conserved hypothetical protein & - \\
\hline Alr1524 & Ribulose bisphosphate carboxylase large chain & $\mathrm{N}_{2}, \mathrm{NO}_{3}^{-}$ & Photosynthesis and respiration & N. punctiforme \\
\hline Alr1548 & Alr1548 protein & $\mathrm{NO}_{3}^{-}, \mathrm{NH}_{4}^{+}$ & Conserved hypothetical protein & - \\
\hline Alr1742 & Chaperone protein DnaK2 & $\mathrm{N}_{2}, \mathrm{NH}_{4}^{+}$ & Cellular processes & - \\
\hline Alr1834 & Alr1834 protein & $\mathrm{N}_{2}, \mathrm{NO}_{3}^{-}, \mathrm{NH}_{4}^{+}$ & Transport and binding proteins & - \\
\hline Alr1965 & ATP phosphoribosyltransferase & $\mathrm{NO}_{3}^{-}, \mathrm{NH}_{4}^{+}$ & Other categories & - \\
\hline Alr2190 & Alpha-amylase & $\mathrm{N}_{2}, \mathrm{NO}_{3}^{-}$ & Other categories & - \\
\hline Alr2313 & Alr2313 protein & $\mathrm{NO}_{3}^{-}, \mathrm{NH}_{4}^{+}$ & No similarity & - \\
\hline Alr2328 & Glutamine synthetase & $\mathrm{N}_{2}, \mathrm{NO}_{3}^{-}, \mathrm{NH}_{4}^{+}$ & Amino acid biosynthesis & N. punctiforme, Anabaena \\
\hline Alr2535 & $\begin{array}{l}\text { Branched-chain amino-acid } \mathrm{ABC} \text { transport } \\
\text { system periplasmic binding protein }\end{array}$ & $\mathrm{N}_{2}$ & Transport and binding proteins & - \\
\hline Alr2709 & Alr2709 protein & $\mathrm{N}_{2}$ & Conserved hypothetical protein & - \\
\hline Alr2771 & Dihydroxy-acid dehydratase & $\mathrm{NO}_{3}^{-}$ & Amino acid biosynthesis & Anabaena \\
\hline Alr2877 & Bicarbonate transport bicarbonate-binding protein & $\mathrm{N}_{2}, \mathrm{NO}_{3}^{-}, \mathrm{NH}_{4}^{+}$ & Transport and binding proteins & - \\
\hline Alr2887 & Alr2887 protein & $\mathrm{N}_{2}, \mathrm{NO}_{3}^{-}$ & Conserved hypothetical protein & - \\
\hline Alr2938 & Superoxide dismutase & $\mathrm{N}_{2}, \mathrm{NO}_{3}^{-}, \mathrm{NH}_{4}^{+}$ & Cellular processes & $\begin{array}{c}\text { N. commune, } \\
\text { N. punctiforme, Anabaena }\end{array}$ \\
\hline Alr2948 & Alr2948 protein & $\mathrm{NO}_{3}^{-}, \mathrm{NH}_{4}^{+}$ & Other categories & - \\
\hline Alr2973 & Glucokinase & $\mathrm{NH}_{4}^{+}$ & Energy metabolism & - \\
\hline Alr3090 & Alr3090 protein & $\mathrm{NH}_{4}^{+}$ & Conserved hypothetical protein & Anabaena \\
\hline Alr3344 & Transketolase & $\mathrm{N}_{2}, \mathrm{NH}_{4}^{+}$ & Other categories & - \\
\hline Alr3402 & Nucleoside diphosphate kinase & $\mathrm{NH}_{4}^{+}$ & $\begin{array}{l}\text { Purines, pyrimidines, nucleosides, } \\
\text { and nucleotides }\end{array}$ & - \\
\hline Alr3539 & Alr3539 protein & $\mathrm{N}_{2}, \mathrm{NO}_{3}^{-}, \mathrm{NH}_{4}^{+}$ & No similarity & Anabaena \\
\hline
\end{tabular}


Table 1. Cont.

\begin{tabular}{|c|c|c|c|c|}
\hline Cyanobase $^{\mathrm{a}}$ & Annotation $^{\mathrm{b}}$ & Growth Condition $^{\text {c }}$ & Functional Category $^{\mathrm{d}}$ & Previously Identified in ${ }^{\mathrm{e}}$ \\
\hline Alr3588 & Alr3588 protein & $\mathrm{NO}_{3}^{-}, \mathrm{NH}_{4}^{+}$ & No similarity & Anabaena \\
\hline Alr3607 & Alr3607 protein & $\mathrm{NO}_{3}^{-}, \mathrm{NH}_{4}^{+}$ & No similarity & - \\
\hline Alr3608 & Alr3608 protein & $\mathrm{N}_{2}$ & Other categories & - \\
\hline Alr3659 & Alr3659 protein & $\mathrm{N}_{2}, \mathrm{NH}_{4}^{+}$ & Energy metabolism & N. punctiforme \\
\hline Alr3808 & Nutrient stress-induced DNA-binding protein & $\mathrm{N}_{2}, \mathrm{NH}_{4}^{+}$ & Other categories & N. commune, Anabaena \\
\hline Alr4072 & Alr4072 protein & $\mathrm{N}_{2}, \mathrm{NO}_{3}^{-}, \mathrm{NH}_{4}^{+}$ & Other categories & - \\
\hline Alr4123 & Phosphoribulokinase & $\mathrm{N}_{2}, \mathrm{NH}_{4}^{+}$ & Photosynthesis and respiration & - \\
\hline Alr4238 & Alr4238 protein & $\mathrm{NH}_{4}^{+}$ & Other categories & Anabaena \\
\hline Alr4385 & Triosephosphate isomerase & $\mathrm{NH}_{4}^{+}$ & Energy metabolism & - \\
\hline Alr4448 & Endo-1,4-beta-xylanase & $\mathrm{N}_{2}$ & Other categories & - \\
\hline Alr4550 & Uncharacterized protein alr4550 & $\mathrm{N}_{2}, \mathrm{NO}_{3}^{-}, \mathrm{NH}_{4}^{+}$ & Conserved hypothetical protein & N. punctiforme, Anabaena \\
\hline Alr4641 & Peroxiredoxin & $\mathrm{NO}_{3}^{-}, \mathrm{NH}_{4}^{+}$ & Cellular processes & Anabaena \\
\hline Alr4745 & Dihydrolipoyl dehydrogenase & $\mathrm{N}_{2}, \mathrm{NO}_{3}^{-}, \mathrm{NH}_{4}^{+}$ & Energy metabolism & - \\
\hline Alr4794 & Alr4794 protein & $\mathrm{NO}_{3}^{-}, \mathrm{NH}_{4}^{+}$ & Conserved hypothetical protein & Anabaena \\
\hline Alr4853 & Aspartate aminotransferase & $\mathrm{N}_{2}$ & Amino acid biosynthesis & - \\
\hline Alr4907 & Ornithine carbamoyltransferase & $\mathrm{N}_{2}, \mathrm{NO}_{3}^{-}, \mathrm{NH}_{4}^{+}$ & Amino acid biosynthesis & - \\
\hline Alr4976 & Phosphodiesterase/alkaline phosphatase D & $\mathrm{NO}_{3}^{-}$ & Other categories & N. commune \\
\hline Alr4979 & Alr4979 protein & $\mathrm{NH}_{4}^{+}$ & Conserved hypothetical protein & Anabaena \\
\hline Alr5103 & LL-diaminopimelate aminotransferase 1 & $\mathrm{~N}_{2}, \mathrm{NO}_{3}^{-}$ & Other categories & Anabaena \\
\hline Alr5182 & Oxidoreductase & $\mathrm{NH}_{4}{ }^{+}$ & Other categories & - \\
\hline Alr7261 & Alr7261 protein & $\mathrm{N}_{2}, \mathrm{NO}_{3}^{-}, \mathrm{NH}_{4}^{+}$ & Other categories & - \\
\hline Alr7346 & Alr7346 protein & $\mathrm{N}_{2}, \mathrm{NH}_{4}^{+}$ & No similarity & - \\
\hline Alr7524 & Alr7524 protein & $\mathrm{N}_{2}, \mathrm{NO}_{3}^{-}, \mathrm{NH}_{4}^{+}$ & Conserved hypothetical protein & - \\
\hline
\end{tabular}

${ }^{a}$ Protein IDs according to Cyanobase (http://genome.microbedb.jp/cyanobase); ${ }^{b}$ protein annotation according to the UniProt database (http://www.uniprot.org/); ${ }^{\mathrm{i}}$ indicates in which growth condition a particular protein has been identified, but should not be considered as a reference to whether that protein is found in that condition only; ${ }^{\mathrm{d}}$ functional category of each exoprotein, as found in Cyanobase (http://genome.microbedb.jp/cyanobase); ${ }^{\mathrm{e}}$ proteins (or orthologues) that have already been identified in previously-studied cyanobacterial exoproteomes or secretomes are highlighted; N. commune, Nostoc commune DRH1 [27]; N. punctiforme, Nostoc punctiforme PCC 73102 [30]; Anabaena, Anabaena sp. PCC 7120 [26]. 
In Sections 3.1.1 and 3.1.2, a detailed analysis and discussion of the different proteins identified is presented, followed by some considerations regarding non-classical protein secretion, namely via outer membrane vesicle formation.

\subsubsection{Analysis of the Anabaena sp. PCC 7120 Identified Exoproteins}

One question to bear in mind when analysing in detail the exoproteome composition of Anabaena sp. PCC 7120 is to know how a particular protein reached the extracellular milieu. Different scenarios may be considered: within the whole group of exoproteins, some may reach the extracellular space via active translocation across the cell wall and accumulate in this environment, because they play a role there. Others may also be translocated across the outer membrane, but instead are structural parts of the cell wall itself (or are involved in cell wall biogenesis) and are released to the extracellular milieu as a result of cell wall turnover. In addition, outer membrane and periplasmic proteins may also contribute to the exoproteome composition as a result of, e.g., passive protein leakage during cell division and cytokinesis, or by rupture of filament integrity, or even by active disposal of non-functional proteins/enzymes. Ultimately, cytoplasmic proteins may also contribute significantly to the composition of the exoproteome: cell death and mechanical shearing may lead to cell lysis. In that case, proteins that do not have a specific function in this environment may simply accumulate outside of the cells during cultivation, because they are relatively stable to proteolysis. However, in this work, knowing exactly how the identified exoproteins ended up in the extracellular milieu remains to be determined. Despite all of our efforts to experimentally minimize the contribution of proteins accumulating in the extracellular space as a result of cell lysis, we cannot exclude that some of the proteins identified are indeed cytoplasmic proteins. Nevertheless, the proteins listed in Table 1 are those identified from gel bands that could be detected consistently across several biological replicates. Thus, the analysis that will follow below regards them as exoproteins, even though the origin and extracellular function (if any) of most require additional experimental work.

A distribution analysis of the proteins listed in Table 1 based on their respective functional categories (Figure 2) reveals that approximately $48 \%$ of the identified exoproteome is classified as "conserved hypothetical" $(20 \%)$, presents no similarity to other proteins $(10 \%)$ or falls into the "other categories" set $(18 \%)$. The latter group of proteins comprises members associated with several unrelated processes, such as "transposon-related functions" and "adaptation and atypical conditions", or are simply categorized as "other". Thus, this group includes proteins with completely different functions and that share no obvious metabolic connection. Overall, the high frequency (48\%) of identified proteins belonging to categories of unknown function further exposes our lack of knowledge regarding the impact of exoproteins and respective extracellular processes on the cell structure and physiology.

Among the identified extracellular proteins with assigned function, it is possible to find various examples of proteins involved in the degradation and processing of different types of biomolecules, including nucleic acids, along with interconversion and salvage of nucleosides (All3791, Alr0069, Alr7261, Alr3402, Alr0051, Alr1299, Alr1520), degradation of proteins and peptides, as well as processes regarding amino acid biosynthesis and processing (All2533, Alr0237, Alr0880, Alr0996, Alr1381, Al14287, Alr1742, Alr4853, Al12315, Alr1004, Alr1313, Alr2771, Alr0608, Alr1080, Alr2328 Alr4907, All1683, Al14464), sugar breakdown and processing (Alr3608, Alr4448, Al13964, All0167, 
All0168, Al10875, Alr0169, Alr2190, Al14539) and phosphor scavenge and transport (Al10207, All2843, All4575, Alr4238, Alr4976). Detection of these proteins suggests that the processes carried out by Anabaena sp. PCC 7120 extracellularly are intimately associated with recycling of valuable nutrients and compounds present in the environment. These substrates may accumulate in the medium as the result of either active secretion across the cyanobacterial cell wall (e.g., extracellular polysaccharides) or by passive release as a consequence of cell lysis. In addition, proteins typically involved in ROS detoxification and redox homeostasis have also been identified, and a detailed analysis and discussion can be found in Section 3.2.
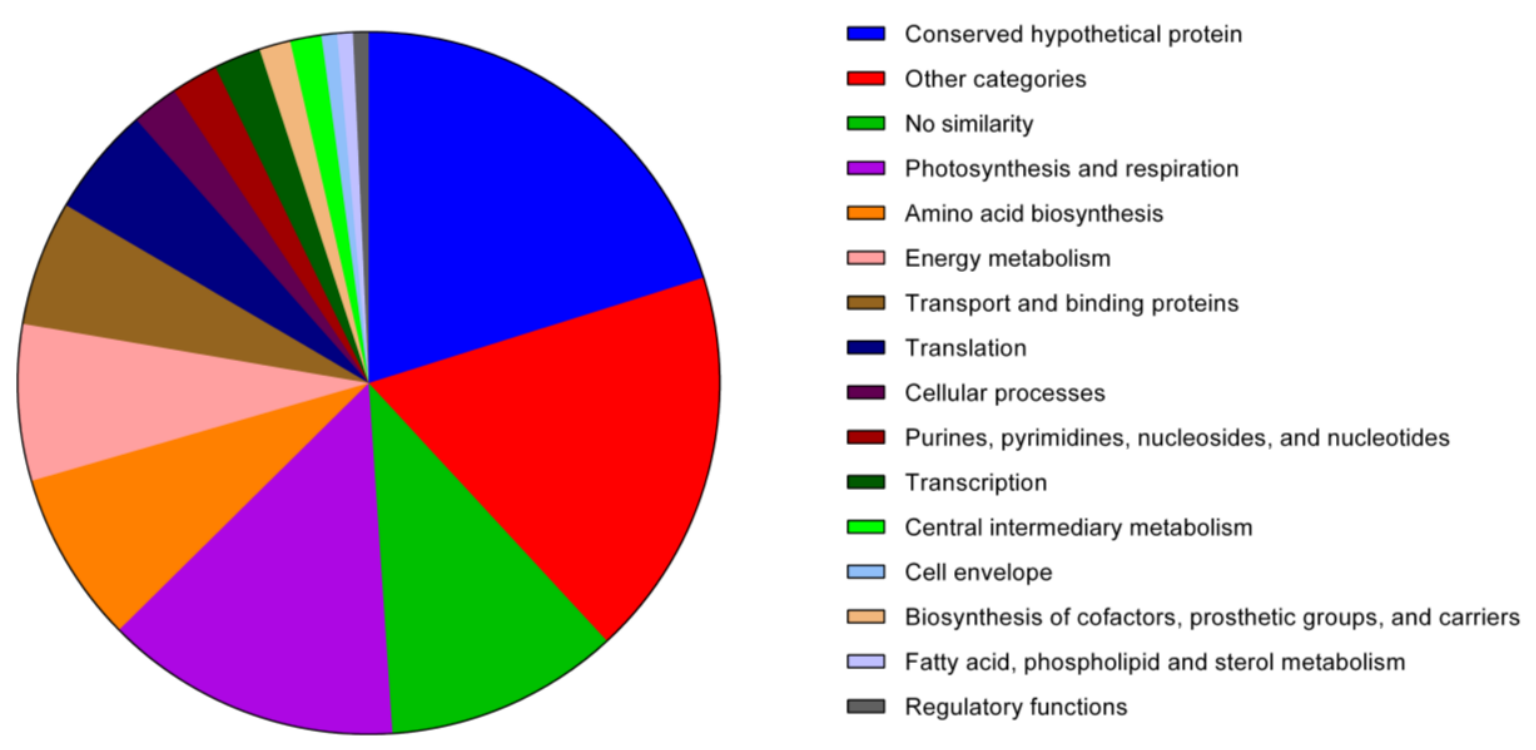

Figure 2. Absolute frequency of the various functional categories (as ascribed by Cyanobase, http://genome.microbedb.jp/cyanobase) of the proteins identified in the exoproteome of Anabaena sp. PCC 7120.

The three growth conditions used to cultivate Anabaena sp. PCC 7120 clearly induced the differential compositions of the exoproteomes (Figure 1). This observation indicates that some proteins are specifically expressed in a given condition and exported to the extracellular milieu to fulfil a particular task. However, the approach adopted and presented here does not allow performing direct comparisons of exoproteome differential compositions between culture conditions. In fact, relative abundance variances analyses should be preceded by better refined and resolved exoproteome separations, e.g., by two-dimensional gel electrophoresis, shotgun proteins and tagging $[14,15,24]$ or label-free workflows [45]. Nevertheless, some differences can be easily identified: for example, Band 7 in the exoproteome of cells grown in BG1 $1_{0}\left(\right.$ Lane $1, \mathrm{~N}_{2}$ ), Bands 5 and 7 in the exoproteome of cells cultivated in BG11 (Lane 2, $\mathrm{NO}_{3}{ }^{-}$) and Bands 7, 9 and 13 in the exoproteome of cells grown in $\mathrm{BG} 11_{0}+\mathrm{NH}_{4}{ }^{+}$ (Lane 3, $\mathrm{NH}_{4}{ }^{+}$) contain proteins that accumulate in higher amounts relatively to the other growth conditions (Figure 1). Based on the number of unique peptides identified for each protein detected in each gel band/gel portion and on its respective protein sequence coverage (see the Supplementary Information), the most abundant protein in Band 7 in BG11 0 is Alr0267. This exoprotein was recently shown to be involved in filament adhesion and aggregation in Anabaena sp. PCC 7120 cells grown in nitrogen-fixing conditions [34]. The protein was named HesF (for heterocyst specific attachment factor), 
and its secretion was shown to be dependent on the TolC-like HgdD protein, part of the type I secretion system [34]. Moreover, the respective gene transcription was shown to be highly upregulated upon a transition from non-nitrogen fixing to nitrogen fixing conditions [34], which could explain the protein's higher abundance in $\mathrm{BG} 11_{0}$ compared to $\mathrm{BG} 11$ or $\mathrm{BG} 11_{0}+\mathrm{NH}_{4}{ }^{+}$. The proteins identified in higher amounts in Band 5 in BG11 and with approximately the same abundance (according to the criteria outlined above; see the Supplementary Information) are Alr0608 (NrtA), the solute-binding component of the high-affinity nitrate $\mathrm{ABC}$ transporter [46], and Alr2877 (CmpA), the bicarbonate transport bicarbonate-binding protein [47]. In a medium containing nitrate, such as BG11, it is not surprising that NrtA is found in higher amounts than in any of the other two growth conditions. Interestingly, Band 7 in BG11 also contains high levels of NrtA, even though the molecular mass of this band is much lower than expected for the full-length NrtA (see the discussion below). Band 7 in $\mathrm{BG}_{1} 1_{0}+\mathrm{NH}_{4}{ }^{+}$, presents an intensity level comparable to Band 5 in BG11; however, the most abundant protein in the former is Alr2877. The gene encoding for protein Alr2877 has been shown to be regulated mainly by the inorganic carbon supply [47]. Nevertheless, it was also shown in the same work that expression of alr2877 is significantly lower in Anabaena sp. PCC 7120 cells experiencing both inorganic carbon and combined nitrogen limiting conditions, as compared to cells growing in a medium limited in inorganic carbon, but replete with combined nitrogen [47]. Thus, these observations could account for the significant differences observed in the amounts of Alr2877 (CmpA) between the exoproteomes of cells cultivated in BG11 and BG11 $1_{0}+\mathrm{NH}_{4}{ }^{+}$and the exoproteome of Anabaena sp. PCC 7120 cells grown in BG110 (see Figure 1 and the Supplementary Information). Finally, and still in $\mathrm{BG} 11_{0}+\mathrm{NH}_{4}{ }^{+}$, Band 9 is majorly Alr0530 (phycobilisome linker polypeptide, phycocyanin associated) and Band 13 is composed mainly of Alr0022 (allophycocyanin subunit beta). The function of these two latter proteins on the extracellular space is unknown; however, it is interesting to notice that the concentrated supernatant of cells grown in BG1 $1_{0}+\mathrm{NH}_{4}{ }^{+}$presented a bluish colour (data not shown), in agreement with the higher amounts of phycocyanin-related proteins. In general, when analysing the list of proteins identified in a given exoproteome, one question frequently raised concerns whether the proteins identified correspond to full-length, active enzymes or if they correspond to proteolytic fragments. To address that point, we have combined the analysis of the SDS-polyacrylamide gel electrophoresis separation of the exoproteome content (Figure 1) with the examination of the proteins identified in each band/area of the gel (see the Supplementary Information) and respective peptides detected by mass spectrometry (see the Supplementary Information). As mentioned above, Band 7 in BG11 is mostly represented by NrtA (Alr0608). NrtA is a lipoprotein that is tethered to the cytoplasmic membrane, facing the periplasm [46]. The NrtA predicted molecular mass is $48 \mathrm{kDa}$, while after cleavage of its signal peptide, it is estimated to be approximately $45 \mathrm{kDa}$ [48], which matches well with the molecular mass of Band 5. However, Band 7 has an estimated molecular mass of $28 \mathrm{kDa}$. After analysing the NrtA, unique peptides detected in Band 5 the amino acid sequence between positions 87 and 422 were covered, while for Band 7, only peptides covering position 184 to 422 were obtained. Therefore, we believe that NrtA in Band 5 may correspond to the full-length protein, while in Band 7, NrtA is most likely an N-terminus truncated proteolytic fragment. Nevertheless, it remains elusive whether proteolysis occurred outside or inside the cell. Another interesting case is the unknown protein Alr0474, detected in the exoproteome of Anabaena sp. PCC 7120 cells grown in medium with nitrate (Bands 6 and 8). While Alr0474 (596 amino acids) peptides found in Band 6 cover amino acid positions 325 to 590, the ones identified in Band 8 
correspond to positions 54 to 189 . These results indicate that Alr0474 is likely to be released to the extracellular milieu and then be subjected to proteolysis. Future exoproteome studies will certainly help to clarify these matters and will further unveil the novel molecular mechanisms of protein turnover and recycling.

Something that cannot go unnoticed is the fact that some exoproteins are encoded by adjacent genes (located in the same or opposite strands) or genes that are located relatively close in the genome. These include cases in which the respective genes are located contiguously and in the same strand, such as Al10004 and Al10005, which are subunits of ATP synthase; Al10167, All0168 and Alr0169 (the first two are encoded by genes located in one strand, while the latter is in the other) are all involved in carbohydrate metabolic processes; A112315 and Al12316 are the ketol-acid reductoisomerase and the aldo/keto reductase, respectively; Alr0020 (phycobilisome subunit), Alr0021 and Alr0022 (both allophycocyanin subunits); and Alr0528, Alr0529 and Alr0530 are phycocyanin-related proteins. Alternatively, we have also registered cases in which the genes are contiguous, but divergently oriented in the genome: All1380 (no similarity) and Alr1381 (calcium-dependent protease); All2533 (prolyl endopeptidase) and Alr2535 (branched-chain amino-acid ABC transport system periplasmic binding protein), even though in this case, the short gene asl2534 is located in between the respective genes; All3538 (enolase) and Alr3539 (unknown protein); All4121 (ferredoxin-NADP(+) reductase) and Alr4123 (phosphoribulokinase), even though the short gene asl4122 is located in between the respective genes; All4906 (phosphoglycerate mutase) and Alr4907 (ornithine carbamoyltransferase); and Alr0267 and All0268, both unknown proteins. In addition, it is also possible to find proteins encoded by genes not located contiguously, but still in very close genomic proximity, such as Al10875 and Alr0878, Al12105 and All2108, All2563 and Al12567, Alr1362 and Alr1364, Alr1520 and Alr1524 and Alr4976, Alr4979 and All4985. It is not uncommon to find contiguous or adjacent genes encoding extracellular proteins in other bacteria (e.g., [49]), but whether these observations in Anabaena sp. PCC 7120 represent fortuitous occurrences or reflect defined molecular mechanisms that may render gene transcription, protein translation and subsequent secretion more efficient remain to be determined.

Another interesting aspect worth mentioning regards the identification of proteins encoded by plasmid-borne genes. Proteins Alr7261 and Alr7346 (the respective genes are in the Alpha plasmid) and Alr7524, All7614 and All7633 (the respective genes are in the Beta plasmid) all belong to one of the categories "conserved hypothetical proteins", "no similarity" or "other functions". Even though the information available about these proteins is scarce, it is remarkable that based on the PSORTb subcellular localization prediction tool [39], Alr7261 is predicted to be an extracellular protein, while the others are predictably periplasmic (All7633), outer membrane (Al17614), cytoplasmic (Alr7524) or unknown (Alr7346) proteins (see the Supplementary Information). In addition, Alr7261 and Alr7524 were found in the exoproteome of Anabaena sp. PCC 7120 cells grown under all tested conditions (Table 1). Despite the general lack of knowledge concerning proteins encoded by plasmid-borne genes, alr7261 putatively encodes an extracellular sugar-non-specific nuclease NucA homologue (Cyanobase), whose most characterized member in Anabaena sp. PCC 7120 is All7362 [50,51]. Alternatively, All7614 has homology to carbohydrate-selective porins (OprB); members of this protein family have been shown in Nostoc punctiforme ATCC 29133 to function as sugar porins, being needed for the optimal uptake of both fructose and glucose [52]. 
The exoproteome of the cyanobacterium N. punctiforme PCC 73102 was recently reported [30]. In that work, the proteins accumulating in the extracellular milieu of cells grown with nitrate or in nitrogen-fixing conditions are presented, in a total of 33 proteins [30]. Furthermore, the secretome analysis of Anabaena sp. PCC 7120 was also recently presented by Hahn and co-workers [26], but they report the detection of secreted proteins (total of 50) from cells grown in a medium containing nitrate. In addition, the extracellular protein content (total of 13 proteins) of Nostoc commune DRH1, another filamentous, heterocyst-forming cyanobacterium, has also been studied, but here, the work was focused essentially on the protein content associated with its extracellular polysaccharide matrix [27]. Approximately $33 \%$ of the proteins identified in the present work have already been detected (or their orthologues) at least in one of the works mentioned above (see Table 1). The extended exoproteome profile presented here, as compared to the ones reported by others, may be accounted for in the three different growth conditions studied. Interestingly, two proteins have been identified in all of the studies focusing on the extracellular proteome of filamentous, nitrogen-fixing cyanobacteria: superoxide dismutase (Alr2938; see the discussion below) and phosphoglycerate kinase (All4131). The latter belongs to the "regulatory functions" category, even though it is a crucial enzyme in the energy metabolism. The presence of this enzyme in the extracellular space of three different cyanobacteria suggests a possible important function in that environment; however, it remains undetermined whether the enzyme is actually active and, if it is, what its function may be in such an environment.

Examining with further detail the work carried out on the secretome of Anabaena sp. PCC 7120, the closest to this work that we could find, a total of $72 \%$ of the proteins identified in that study could also be detected in this work. From those, it is worth referencing that proteins belonging to the categories "photosynthesis and respiration" (including ATP synthase and various phycobilisome subunits), "amino acid biosynthesis", "central intermediary metabolism" (including phosphoglucomutase/phosphomannomutase and ribulose-phosphate 3-epimerase) and "energy metabolism" (transaldolase, glucose-6-phosphate isomerase and enolase) are found in both studies, supporting the notion that these proteins are indeed part of the exoproteome, despite being part of the primary metabolism of the organism. From the secreted proteins reported [26] that were not identified here, we can highlight Al10070, a Mn-containing superoxide dismutase whose activity we were able to detect instead in the exoproteome (see below), a ferritin-like Dps protein (All1173), while here, we found instead the ferritin-like Dps proteins, All0458, Alr3808 and All4145; and the putative alkaline phosphatases, Alr2234 and Alr5291; while in our work, we identified All0207 and Alr4976.

\subsubsection{Membrane Vesicle Formation}

When analysing the proteins identified in the various exoproteome samples of Anabaena sp. PCC 7120 (Table 1) and also reported by others [26,27,30], we could find several proteins predicted to be localized in the cytoplasm (Supplementary Information). Furthermore, few outer membrane proteins could also be observed in the exoproteome (Supplementary Information). At first glance, detection of such proteins in the extracellular space seems to be an indication of cell lysis and the passive release of proteins to the extracellular space, as already highlighted above. Nevertheless, identification of predicted cytosolic proteins in the extracellular milieu has been reported several times in a wide spectrum of bacteria, e.g., [53-58]. In the case of Anabaena sp. PCC 7120, the extracellular processes are so poorly 
studied and understood that it is possible that some of these proteins are indeed actively secreted [26], fulfilling a specific function yet to be described. Alternatively, it may also represent a mechanism for the removal of such proteins (or respective proteolytic degradation products) from the cytoplasm [26] or other subcellular locations (e.g., see NrtA, discussed above).

A good example to demonstrate how much is unknown in terms of extracellular processes is outer membrane vesicles (OMV) formation. A large number of heterotrophic Gram-negative bacteria naturally produce OMV, spherical bilayered vesicles released from the outer membrane, ranging in size from 50 to $250 \mathrm{~nm}$ in diameter [59]. Their suggested functions include toxin trafficking, DNA transfer and uptake, protein delivery and communication (reviewed by $[59,60]$ ). OMV formation by photoautotrophs was not described until earlier in 2014, when Biller and co-workers [61] were able to show it in cyanobacteria of the genera Prochlorococcus and Synechococcus. In that work, not only cultures of Prochlorococcus were shown to continuously release lipid vesicles containing proteins, DNA and RNA, but also that these vesicles could be found abundantly in coastal and open-ocean sea water samples. Most interestingly, Prochlorococcus vesicles were demonstrated to support the growth of heterotrophic bacteria, as well as to have the capacity of being recognized and infected by cyanophages [61]. Thus, as recognized by the authors, the ability to form vesicles by marine photoautotrophs adds another layer of complexity to the flow of information, energy and biomolecules in marine microbial ecosystems [61]. However, this may not be restricted to marine ecosystems, if OMV formation proves to be a common mechanism widespread to other cyanobacteria occupying different ecological niches. Proteomic analyses of Prochlorococcus MED4 vesicles identified a diverse set of proteins, including membrane nutrient transporters and porins, but also, predictably, soluble proteases and hydrolases and several proteins of unknown function [61]. Interestingly, from the 40 Prochlorococcus MED4 reported vesicle proteins, eight homologues could be found in the exoproteome of Anabaena sp. PCC 7120, including the porin TolC-like HgdD (Alr2887), the membrane transporters All4575 (phosphate), All1951 (ABC-type) and All4388 (putative polysaccharide exporter), the phosphoribosylglycinamide formyltransferase 2 (Alr1299), the ATP synthase $\alpha$-subunit (All0005), the RuBisCO large subunit RbcL (Alr1524) and the hypothetical protein, Al10268. Furthermore, it is also noteworthy that even though it was not possible to find the respective homologues for some of the Prochlorococcus MED4 vesicles' proteins, related counterparts could be found for proteases (Alr1381, Alr0996), aminotransferases (Al11683, Alr1004, Alr1080, Alr4853, Alr5103) and even ribosomal proteins (Al14214) (see the Supplementary Information). Until now, there have been no reports describing the ability of Anabaena sp. PCC 7120 to form and release vesicles. Therefore, the different Anabaena sp. PCC 7120 concentrated exoproteome samples were subjected to negative staining transmission electron microscopy, in an attempt to find OMVs. Remarkably, the three samples presented numerous small spherical structures (Figure 3) that strongly resemble the membrane vesicles reported for Prochlorococcus [61].

This observation, together with the detection of membrane vesicles in the Synechocystis sp. PCC 6803 concentrated exoproteome (data not shown; [62]), suggests that outer membrane vesicle formation may represent an ability widely distributed in cyanobacteria. Hence, we propose that the set of membrane vesicles' proteins identified in Prochlorococcus MED4 that could also be found in the exoproteome of Anabaena sp. PCC 7120 may be considered as part of the cyanobacterial membrane vesicle proteome core. However, Prochlorococcus and Anabaena are cyanobacterial genera that occupy very different 
ecological niches (marine vs. freshwater), present obvious morphological differences (unicellular vs. filamentous) and have different capabilities concerning cellular differentiation (no differentiated cells $v s$. heterocysts). In addition, the genome size of Prochlorococcus MED4 is approximately $2.4 \mathrm{Mbp}$, while the one of Anabaena sp. PCC 7120 is about three-times larger (7.2 Mbp). These differences may contribute to membrane vesicle proteomic variances and even account for an extended membrane vesicle proteome repertoire in organisms with larger genomes and more complex lifestyles. Therefore, it is possible that other proteins identified in the present work may also be originating from membrane vesicles. However, this will only be elucidated after the Anabaena sp. PCC 7120 outer membrane vesicles' proteome becomes fully characterized. Therefore, in some prokaryotes, membrane vesicle formation represents a useful, highly efficient and effective, but yet largely overlooked, instrument of protein secretion: the fact that soluble proteins included in the OMV lumen, as well as bound to the OMV surface are co-released with insoluble material (lipids) may represent a protective mechanism, by which OMV-mediated transport can allow less stable molecules, such as protease-susceptible proteins, to reach their destination or behave like time-release capsules, which provide a beneficial activity at a later time [60]. Even more interesting is the capacity of OMV to be specifically targeted to a particular distal site through the binding specificity between surface-exposed bacterial proteins and environmental ligands or receptors [60].

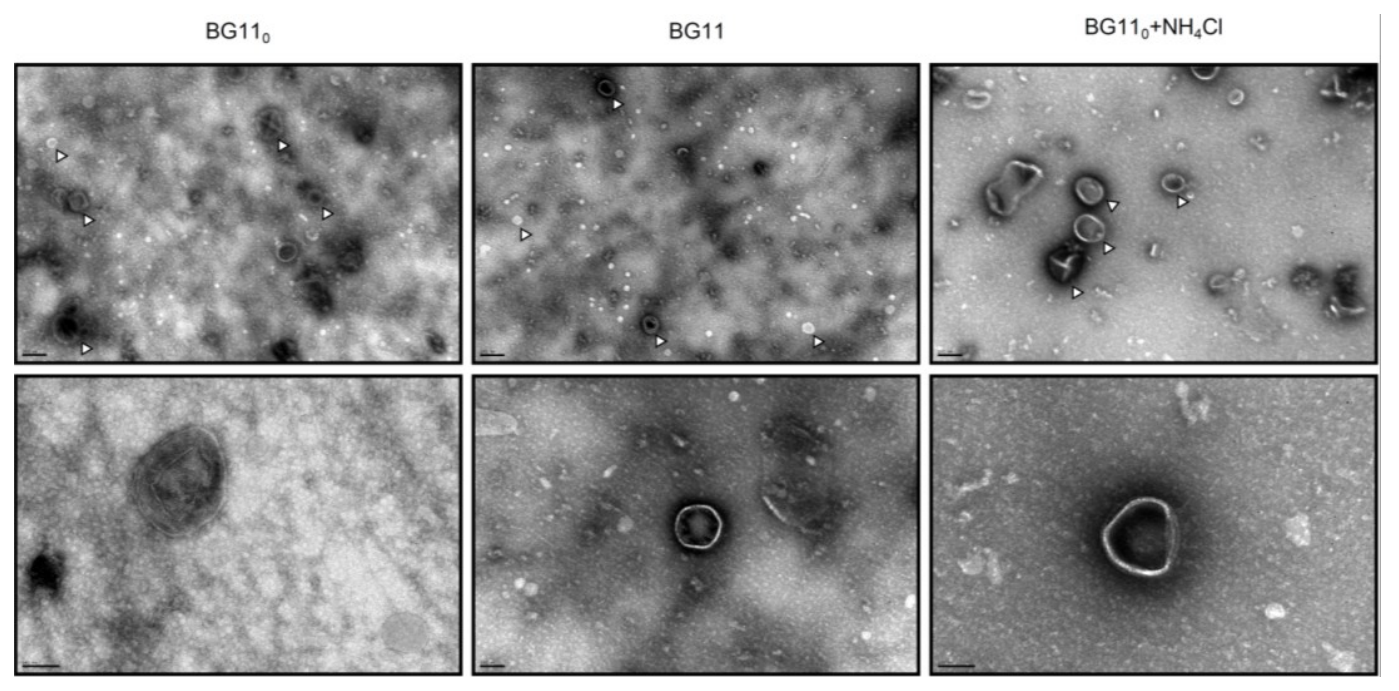

Figure 3. Negative staining electron micrographs of Anabaena sp. PCC 7120 concentrated exoproteome samples collected from cultures grown in nitrogen-fixing conditions (BG110), or in medium supplemented with nitrate (BG11) or ammonia (BG11 $\left.1_{0}+\mathrm{NH}_{4} \mathrm{Cl}\right)$. (Top) The presence and abundance of outer membrane vesicles (some highlighted by white arrowheads) in each sample (size bar, $200 \mathrm{~nm}$ ); (bottom) the details of selected vesicles (size bar, $100 \mathrm{~nm})$.

\subsection{Cyanobacterial Exoproteins Involved in Redox Homeostasis}

One aspect on which we focused our attention was the identification in the extracellular milieu of proteins typically involved in ROS detoxification and redox homeostasis. The identified exoproteins include the Fe superoxide dismutase (Fe-SOD-Alr2938), a hypothetical Mn-catalase (Alr3090), 
a peroxiredoxin (Alr4641), the ferritin-like, nutrient stress-induced DNA binding proteins All0458, Alr3808 and All4145 and glutathione reductase (All4968).

The ability of prokaryotes to export ROS protein scavengers to the extracellular space is well documented in the literature, particularly for pathogenic bacteria, such as mycobacteria [63,64], streptococci [65], Campylobacter [66] and Corynebacterium [58]. Since phagocytic cells produce reactive oxygen intermediates to kill invading bacteria, it is not surprising that these enzymes are important for virulence [63,64]. In contrast, reports describing the presence and activity of ROS detoxifying proteins in the extracellular space of cyanobacteria are limited to the work of Shirkey et al. [67]. In this work, the exudates (supernatant fractions) of desiccated colonies of $N$. commune ENG/1996 and cultures of $N$. commune DRH1 were shown to have high amounts of SOD, as well as high levels of enzyme activity [67]. It was also demonstrated that the extensive extracellular polysaccharide matrix of $N$. commune DRH1 generated superoxide radicals upon exposure to ultra-violet irradiation [67]. Hence, it was proposed that the SOD released by $N$. commune is crucial for the cyanobacterium to deal with the oxidative stress imposed by multiple cycles of desiccation and rehydration of the extracellular matrix during ultra-violet irradiation in situ [67]. Anabaena sp. PCC 7120 does not form a complex extracellular polysaccharide matrix similar to that described for $N$. commune strains, and still, SOD could be identified accumulating in the extracellular space. Fe-SOD was detected in the exoproteomes of cells grown under all tested conditions (Table 1) and not just in the exoproteome of cells grown under conditions eliciting the synthesis and secretion of large amounts of polysaccharides, as in nitrogen-fixing conditions. Therefore, we have decided to evaluate whether SOD activity could be detected in the three isolated exoproteomes. Our in-gel activity results clearly show the presence of SOD activity in all three isolated exoproteomes (Figure 4); in addition to the clear SOD activity band, other fainter bands/smear could also be observed (Figure 4A). We hypothesized that the additional fainter bands could be resulting from the activity of Fe-SOD (Alr2938) and Mn-containing SOD (All0070; not identified in this work) complexes. To test that hypothesis, the Fe-SOD activity was inhibited with the presence of $\mathrm{H}_{2} \mathrm{O}_{2}$; in such conditions, the intensity of the clearest SOD activity band completely disappeared, as well as part of the signal from the other fainter bands/smear, remaining however as part of the signal (Figure 4B). This result supports our initial suggestion that Fe-SOD and the Mn-containing SOD may indeed form complexes in the extracellular milieu.
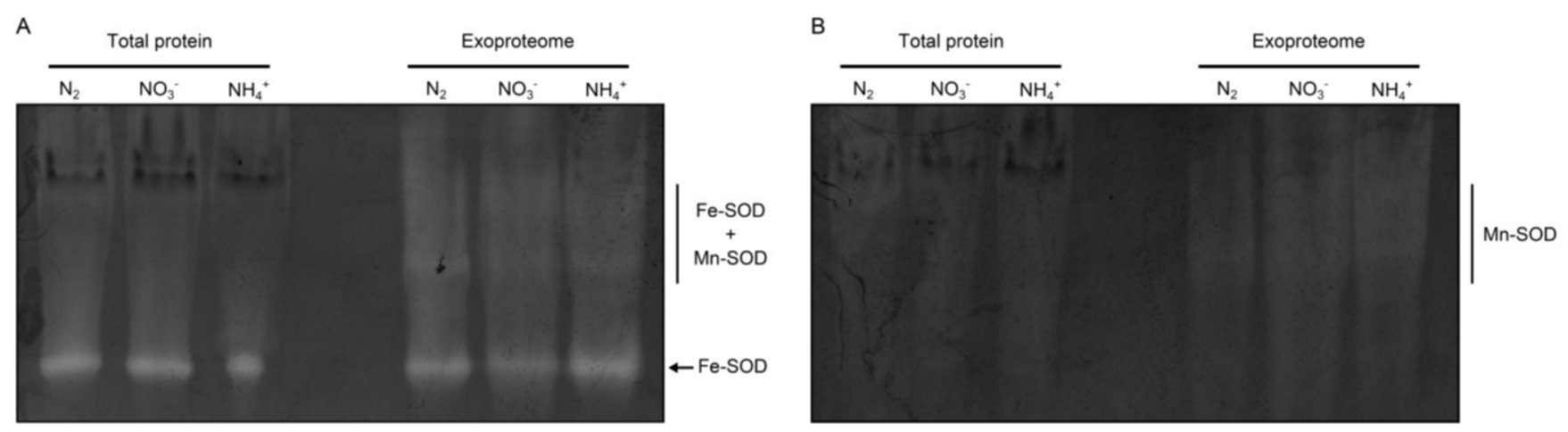

Figure 4. In-gel analysis of the SOD activities of Anabaena sp. PCC 7120. Cells were grown in nitrogen-fixing conditions $\left(\mathrm{N}_{2}\right)$ or in medium with nitrate $\left(\mathrm{NO}_{3}{ }^{-}\right)$or ammonia $\left(\mathrm{NH}_{4}{ }^{+}\right)$. Cell-free extracts were obtained from the collected cells, while the exoproteome was 
concentrated from the respective cell-free medium. Three hundred micrograms of total protein (total protein) and the protein content present in approximately $20 \mathrm{~mL}$ of culture (exoproteome) were separated by native-polyacrylamide gel electrophoresis. (A) Zymogram depicting total SOD activity. The Fe-SOD and Fe-SOD/Mn-SOD complexes' activity bands are highlighted; (B) Zymogram showing the SOD activity bands, as a result of the specific inhibition of Fe-SOD with $5 \mathrm{mM} \mathrm{H}_{2} \mathrm{O}_{2}$ [41]. The Mn-SOD activity bands/smear are highlighted.

In addition to the detection of Fe-SOD protein in the extracellular space of Anabaena sp. PCC 7120 (both in this work and in [26]) and in N. commune ENG/1996 and N. commune DRH1 [27,67], an SOD homologue was also identified recently in the exoproteome of $N$. punctiforme PCC 73102 [30]. Based on these results, it is tempting to assume that secretion of SOD may be a generalized mechanism adopted by cyanobacteria. The exoproteome of the unicellular, freshwater, non-nitrogen-fixing cyanobacterium, Synechocystis sp. PCC 6803, was isolated as described for Anabaena sp. PCC 7120, and the SOD activity was equally assessed by zymography. However, no SOD activity bands could be observed in Synechocystis sp. PCC 6803 (data not shown), suggesting that only a limited number of cyanobacterial species (thus far limited to filamentous and heterocyst-forming strains) are capable of exporting and accumulating active SOD in the extracellular milieu, at least under the conditions tested.

We have also extended our analyses to evaluate catalase activity (Figure 5). Our results indicate that some factor in the Anabaena sp. PCC 7120 growth medium does possess the capacity of decomposing $\mathrm{H}_{2} \mathrm{O}_{2}$ (Figure 5), likely catalase. These results validate the identification of Alr3090 in the exoproteome of Anabaena sp. PCC 7120 and further support the suggestion that a complex oxidative stress defence mechanism exists extracellularly in this cyanobacterium. Nevertheless, total catalase activity levels determined here are low as compared to what is described for other cyanobacteria [68,69], even when using total protein extracts (Figure 5). However, catalase has been shown not to be the main mechanism to cope with $\mathrm{H}_{2} \mathrm{O}_{2}$ by the filamentous, heterocyst-forming cyanobacterium, Anabaena sp. PCC 7120; instead, peroxiredoxins are reported to be the main $\mathrm{H}_{2} \mathrm{O}_{2}$ detoxifying pathway [70], one of which (Alr4641) has been identified in the exoproteome of Anabaena sp. PCC 7120 (see the discussion below).

Total Protein

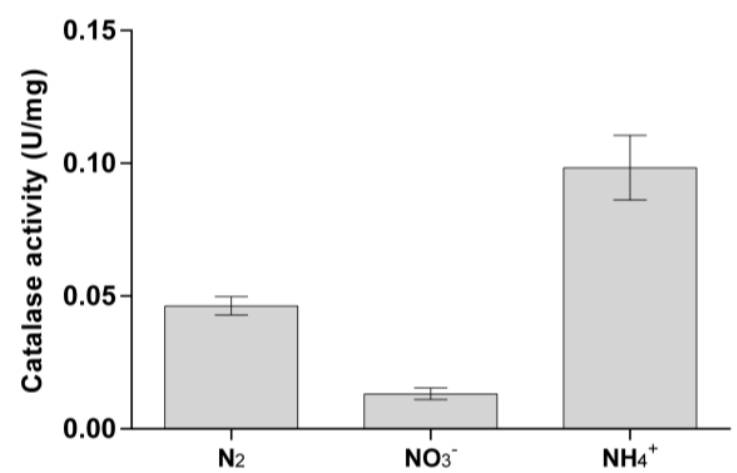

\section{Exoproteome}

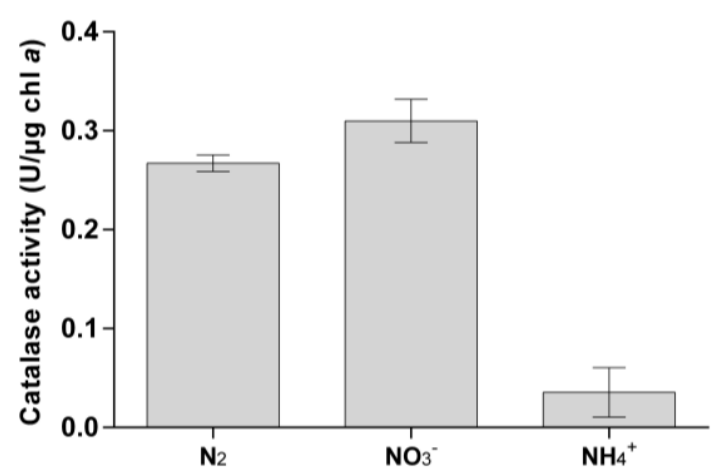

Figure 5. Catalase activity measured in cell-free extracts (total protein) or in concentrated exoproteomes of Anabaena sp. PCC 7120. Activities are expressed as units (defined as the amount of enzyme that catalyses the dissociation of $1 \mu \mathrm{mol}$ of $\mathrm{H}_{2} \mathrm{O}_{2}$ per minute) per mg of total protein (left) or units per $\mu \mathrm{g}$ chlorophyll $a$ (right). 
These results combined indicate that Anabaena sp. PCC 7120 is dealing with oxidative stress even outside of the cells. This notion may not be surprising for cyanobacteria in defined ecological circumstances, such as in mats, biofilms, symbiotic associations or even when free-living in freshwater bodies or marine ecosystems, since competition with other microorganisms for nutrients and even other cyanobacteria for light may involve ROS release and attack. However, in controlled laboratory conditions, in which the organism is cultivated axenically, it becomes difficult to interpret the observation that Anabaena sp. PCC 7120 exports and accumulates such high amounts of functional ROS detoxifying agents. Consequently, we became interested in analysing the ROS usually formed in normal growth medium under ordinary cultivating conditions, but without the presence of cells. Thus, the three media used to grow Anabaena sp. PCC $7120\left(\mathrm{BG} 11_{0}, \mathrm{BG} 11, \mathrm{BG} 11_{0}+\mathrm{NH}_{4}{ }^{+}\right.$) were kept sterile in the same conditions as cyanobacterial cultures. ROS levels were determined using the fluorescent redox indicator, DCF (dichlorodihydrofluorescein) (Figure 6).

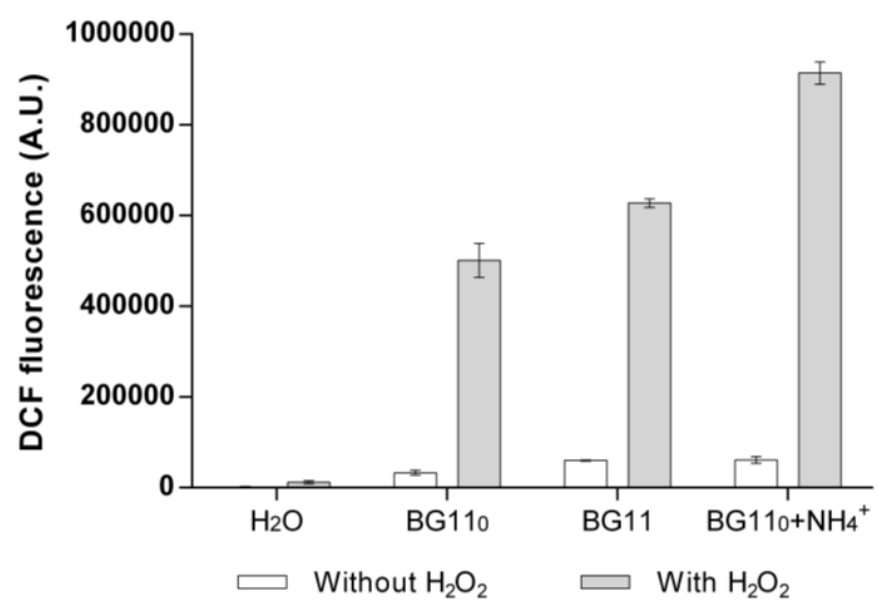

Figure 6. Reactive oxygen species (ROS) level determination in sterile cyanobacterial growth medium. Fluorescence of the molecular probe, DCF, which is directly related to its oxidation state and to the amount of ROS in the medium, was used to measure total ROS levels (A.U., arbitrary units). Cyanobacterial media BG1 $1_{0}$, BG11 and BG11 $1_{0}+\mathrm{NH}_{4}^{+}$were kept sterile under the same conditions of temperature and aeration as cyanobacterial cultures. Water was used as the control. White bars, water or medium without $\mathrm{H}_{2} \mathrm{O}_{2}$; grey bars, water or medium with $0.5 \mathrm{mM} \mathrm{H} \mathrm{O}_{2}$. Given the heterogeneity in DCF fluorescence between different experiments, the data shown are from a single experiment, but the observed pattern is typical (at least three separate observations). The bar values are means, and the error bars correspond to the standard deviation from three technical replicates.

Interestingly, as compared to distilled and deionized water, all three media presented higher levels of total ROS as indicated by a higher DCF fluorescence (Figure 6). In addition, all media presented approximately the same DCF fluorescence levels (white bars in Figure 6), suggesting that all present about the same amount of ROS. In order to monitor the probe's responsiveness to the presence of ROS, $0.5 \mathrm{mM} \mathrm{H}_{2} \mathrm{O}_{2}$ were added exogenously to each medium and to water. The addition of $\mathrm{H}_{2} \mathrm{O}_{2}$ induced a much stronger fluorescence signal in any of the tested media as compared to water. Despite its evident utility and simplicity of use, DCF presents some disadvantages, one of which lies in its differential fluorescence response to various ROS (Life Technologies). This could account for the differences 
observed between water supplemented with $\mathrm{H}_{2} \mathrm{O}_{2}$ and all tested media supplemented with $\mathrm{H}_{2} \mathrm{O}_{2}$ : since the reference BG11 medium is composed of minerals and several metals in solution [33], it is possible that $\mathrm{H}_{2} \mathrm{O}_{2}$ reacts with, e.g., iron $\left(\mathrm{Fe}^{2+}\right)$ present in the medium in the so-called Fenton reaction, resulting in the formation of hydroxyl radicals. The DCF redox indicator has been shown to respond approximately 40-times more efficiently to the presence of hydroxyl radicals than to $\mathrm{H}_{2} \mathrm{O}_{2}$ (Life Technologies). Overall, these results show that ROS are generated naturally in ordinary cyanobacterial growth medium (something also observed for cultivating media of other organisms; [71] and the references therein) and that the interaction of $\mathrm{H}_{2} \mathrm{O}_{2}$ with medium components generates additional ROS. Moreover, these results also show that some cyanobacteria may release enzymes into the extracellular milieu to specifically detoxify exogenous ROS.

Regarding the other proteins involved in redox homeostasis identified in the exoproteome, the peroxiredoxin Alr4641 (2-Cys Prx) has been suggested to be the main mechanism by which Anabaena sp. PCC 7120 is capable of coping with $\mathrm{H}_{2} \mathrm{O}_{2}$, which presents abundant and sensitive intracellular levels of 2-Cys Prx, but low catalase activity [70]. Therefore, it may be possible that Anabaena sp. PCC 7120 secretes both catalase and 2-Cys Prx in order to cope efficiently with $\mathrm{H}_{2} \mathrm{O}_{2}$ exposure.

Furthermore, proteins Al10458, Alr3808 and All4145 are ferritin-like, nutrient stress-induced DNA binding proteins (Dps). One of the main components providing structural integrity to biofilms, in addition to exopolysaccharides and proteins, is extracellular DNA [72]. Interestingly, Dps proteins have been shown to have an important role in Campylobacter jejuni in vitro biofilm formation [73], and Dps proteins have been identified in the exoproteomes of Staphylococcus aureus [74] and Bacillus anthracis [75] and even in the OMV of Brucella melitensis [76]. Thus, it is possible that Anabaena sp. PCC 7120 releases DNA to the extracellular space to promote biofilm formation, and Dps proteins are simultaneously translocated to protect extracellular DNA from structural damage elicited by oxidative stress.

Finally, the glutathione reductase (All4968) is the enzyme that catalyses the reduction of glutathione disulfide to glutathione with NADPH as the reducing cofactor. Glutathione is an extremely important antioxidant agent, preventing the damage of core cellular components caused by ROS. Interestingly, glutathione reductase has also been found in the exoproteome of the marine bacterium, Roseobacter sp. MED193 [77]. However, the presence of the protein in the extracellular milieu is rather puzzling: if glutathione may indeed play a role in maintaining redox homeostasis in the extracellular environment as a protection barrier in the cell vicinity against ROS (and, in fact, a bacterial glutathione transporter has been reported to export reductant to the periplasm of Escherichia coli [78]), it becomes difficult to interpret how glutathione reductase may be active when glutathione disulfide and reducing power in the form of NADPH are required. Additional work is needed to shed light on whether glutathione reductase is actively secreted by Anabaena sp. PCC 7120 and, if so, what may be the physiological impact/advantage of All4968 presence in the extracellular milieu of this cyanobacterium.

In general, it remains to be elucidated how these identified proteins involved in ROS detoxification and redox homeostasis reach the extracellular space, since no leader peptides can be detected in their primary amino acid sequences. One possibility could be that these proteins represent non-classical secreted proteins, and so, their secretory mechanisms remain elusive; alternatively, their transport to the 
extracellular milieu may be mediated by OMV, as described for SOD in B. melitensis [76] and Acinetobacter baumannii [79].

\subsection{Modulating Cyanobacterial Protein Secretion: Future Perspectives}

The competence for secreting proteins to the extracellular milieu is not exclusive to cyanobacteria, and it has already been used in certain prokaryotes to produce and secrete selected protein targets. In the case of applications where purified recombinant proteins are used directly, secretion of these proteins extracellularly could significantly reduce the complexity of a production process by eliminating the need for cell lysis and reducing the burden of removing host proteins [80]. Furthermore, secretion of highly expressed proteins minimizes the formation of inclusion bodies, aids in folding, allows for disulfide bond formation, reduces the effects of intracellular protein degradation and lessens the detrimental effects of cytotoxic proteins (reviewed by [80]).

Given the extraordinary physiological, metabolic and genetic qualities presented by cyanobacteria, we believe that if properly engineered, protein secretion by these photoautotrophs represents an attractive approach to further explore biotechnological solutions. In fact, the ability of cyanobacteria to use sunlight and carbon dioxide as energy and carbon sources, respectively, together with faster growth rates (compared to plants) and the relative ease with which they can be genetically engineered (compared to algae), make cyanobacteria stand out from all other organisms so far used in biotechnological applications [44,81]. In particular, cyanobacterial protein secretion may be a valuable alternative for solving various challenges in bioremediation, biomass recovery and biofuel production.

In addition to the strategies already in course for using cyanobacteria as efficient agents of bioremediation (e.g., making use of their exopolysaccharides [82]), cyanobacterial protein secretion could contribute significantly towards that goal; for example, nitrogen-fixing cyanobacteria could be genetically modified to express and secrete specific heavy metal chelators, contributing to detoxifying heavy-metal contaminated soils, as well as enriching their combined nitrogen content.

In order to reach commercially attractive figures in cyanobacteria-based biotechnological applications, the cultivation of cyanobacteria needs to be done at a large scale, which brings the issue of biomass recovery in large culture volumes. One of the strategies to separate growth medium from the valuable biomass has been to trigger cyanobacterial cells to adhere, aggregate and flocculate, easing its recovery. Some studies have shown that cyanobacterial cells adhesion and aggregation are facilitated by extracellular proteins [28,31,34]; thus, activation of those exoproteins expression and secretion with a precisely defined timing may aid in biomass recovery and reduce total biomass production costs.

In the case that whole microbial cells expressing recombinant proteins are used to interact with a polymeric material, extracellular secretion of proteins is necessary due to the inability of microbial cells to uptake polymer substrates [80]. Therefore, deconstruction of, e.g., polymeric lignocellulosic biomass to fermentable sugars is an important area with increasing interest in biofuel production from renewable resources. In this case, "polysaccharase" or "cellulase" secreting cyanobacteria would contribute to degrading these complex polymeric substances to simpler sugars; since cyanobacteria are capable of fixing their own carbon, products of lignocellulosic deconstruction would not be taken up by cyanobacteria, being instead fully available for other, more suitable fermenting bacteria that could then convert the recently released sugars into valuable biofuels. 
In free-living nitrogen-fixing cyanobacteria, once atmospheric nitrogen is fixed to ammonia and assimilated to glutamine, it is believed to be partly converted to arginine, which is then polymerized into cyanophycin [83]. Cyanophycin synthesis after nitrogen fixation has been suggested to serve an important function by removing from solution the products of nitrogen fixation, which could have a negative feedback effect on nitrogenase $[83,84]$. Analogously, generating nitrogen-fixing cyanobacteria capable of secreting large amounts of a target protein would cause the organism to be drained off of fixed nitrogen and probably relieve repression and feedback on nitrogen fixation. Consequently, from the continuous protein secretion, one could expect higher nitrogen fixation rates and/or extended periods of nitrogenase activity to sustain growth, which would be an advantage for nitrogenase-based technological processes, such as the production of molecular hydrogen, a by-product of nitrogenase activity [85].

Investigations recently carried out in our laboratory strongly indicate that there is room for engineering and modulating cyanobacterial protein secretion. As presented in Figure 7, the simple fusion of a nitrate inducible promoter with the exoprotein encoding gene, hes $F$, resulted in the overexpression of the protein, leading to an over-accumulation of HesF in the extracellular milieu. Furthermore, this result also highlights that even though a signal peptide could not be identified in the sequence of HesF, whatever addresses the protein for secretion seems to be highly efficient [34].

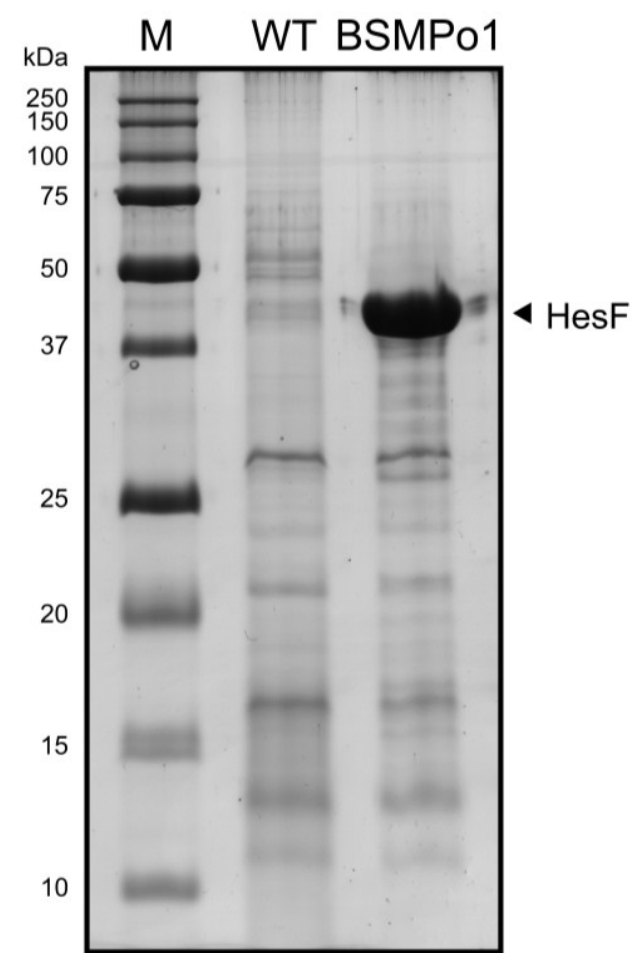

Figure 7. Exoproteome profiles of Anabaena sp. PCC 7120 wild-type (WT) and BSMPo1 [34] cultivated in BG11. The Coomassie-stained SDS-polyacrylamide gel shows the exoproteome of both strains grown for three days in a medium containing nitrate. The protein content present in approximately $3 \mathrm{~mL}$ of the growth medium was loaded on each lane. The molecular masses of the Precision Plus Protein All Blue standard (Bio-Rad), Lane $\mathrm{M}$, are indicated on the left, while the arrowhead points to the overexpressed and secreted protein HesF. 
In order to explore protein secretion by cyanobacteria, a number of aspects need to be addressed and finely tuned. As for other bacterial systems, signal peptides or protein determinants that can address the translocation of a newly-synthesized protein from the cyanobacterial cytoplasm to the extracellular space represents one of the most crucial steps towards optimization of the secretion process. Signal peptides recognized by specific secretion systems are described for some bacteria (for a review, see [80]), and these could be tested and validated in cyanobacteria. Alternatively, in the specific case of HesF presented above, no signal peptide could be identified, and still, it must bear an efficient secretion determinant judging by the amounts of protein that accumulated in the growth medium. This represents a good example of how screening for novel signal peptides may open the door to more efficient secretion systems. Another aspect that deserves close attention when designing a protein secretion module is the selection of a promoter that will drive the transcription of the protein of interested coding gene. Cell-type specificity (in the case of cyanobacteria with the capacity of cellular differentiation), timing of expression and promoter strength are just a few of the points that need to be considered and coordinated with the particular protein to be secreted. Efforts to design suitable promoters for the most varied purposes and applications in cyanobacteria are being made [86,87] and will surely aid in engineering competent protein secretion microorganisms.

However, a few challenges loom ahead before successful implementation of engineered cyanobacterial cells to secrete selected target proteins can be attained. Vilhauer and co-workers showed that proteases are present and active in the extracellular space of Nostoc punctiforme, demonstrating as well that the extent of such proteolytic activity was dependent on the growth condition [30]. Thus, extracellular protease activity has to be considered and duly evaluated, so as to avoid poor protein recovery yields, low quality protein purifications or extracellular modules of low functionality, depending on the final application of the secreted protein. Still, this may be overcome by a balanced regulation between the rate of gene transcription, protein expression and protein secretion, as well as the rate of protein degradation, similarly to what happens in the cytoplasm of protein-(over)expressing bacteria. Moreover, the natural production and release of polysaccharides by cyanobacterial cells may also represent an obstacle towards the use of secreted proteins to fulfil particular goals.

Finally, the membrane vesicles that Anabaena sp. PCC 7120 is shown here to be able to produce represent an additional point of interest regarding protein secretion. The molecular mechanisms behind membrane vesicle formation, including the cellular structures and components responsible for packing those vesicles or even the determinants that govern what goes in and what remains out of the vesicles, are completely unknown in cyanobacteria. However, it is tempting to imagine the possibility of cyanobacteria forming membrane vesicles enriched in a target cargo that has been recombinantly produced: not only would this ease purification and increase the stability of the cargo, but also the membrane vesicles could act as delivery vectors. Certainly, many fundamental aspects need to be clarified before it becomes possible to be fully explored, but such a scenario is not completely unrealistic, since the delivery of foreign antigens by engineered outer membrane vesicle vaccines has already been demonstrated [88]. 


\section{Conclusions}

The exoproteome of the filamentous, heterocyst-forming cyanobacterium, Anabaena sp. PCC 7120, grown in nitrogen-fixing conditions or in medium supplemented either with nitrate or ammonia is presented in this work. Strikingly, as many as 139 proteins have been identified, belonging to 16 different functional categories. Proteins involved in oxidative stress detoxification and redox homeostasis are among the identified exoproteins, including SOD and catalase, whose activities we were able to detect in the concentrated supernatant. This suggests that Anabaena sp. PCC 7120 invests valuable cellular resources to eliminate reactive oxygen species, even outside of the cell. Furthermore, Anabaena sp. PCC 7120 is shown here, for the first time, to be able to release outer membrane vesicles that likely contribute to the whole exoproteome content. Finally, cyanobacteria seem to have the potential of becoming robust protein secretion factories, and future studies focusing on the cyanobacterial exoproteome will certainly contribute towards that goal.

\section{Acknowledgments}

We wish to express our gratitude to Rui Fernandes and Franscisco Figueiredo (IBMC) for practical help with electron microscopy analyses and the Parasite Disease group (IBMC) for the use of the Synergy 2 microplate reader. This work was funded by FEDER funds through the Operational Competitiveness Programme, COMPETE, and by National Funds through FCT, Fundação para a Ciência e a Tecnologia, under the scholarships, SFRH/BPD/74894/2010 (Paulo Oliveira) and PTDC/BIA-MIC/2889/2012-PR451402-BIL (Marina Santos). Nuno M. Martins acknowledges financial support by the European Union under the Erasmus program (2013). Phillip C. Wright and Narciso Couto acknowledge the Engineering and Physical Sciences Research Council (EPSRC) for funding under the Chemical Engineering at the Life Science Interface (ChELSI) and S\&I award (EP/E036252/1).

\section{Author Contributions}

Paulo Oliveira, Nuno M. Martins, Marina Santos, Phillip C. Wright and Paula Tamagnini conceived and designed the experiments. Nuno M. Martins, Paulo Oliveira, Marina Santos and Narciso A. S. Couto performed the experiments. Nuno M. Martins, Paulo Oliveira, Marina Santos and Narciso A. S. Couto, Phillip C. Wright and Paula Tamagnini analysed the data. Paulo Oliveira, Narciso A. S. Couto, Phillip C. Wright and Paula Tamagnini contributed to the writing of the manuscript. All authors have read and approved the final manuscript.

\section{Supplementary Materials}

Supplementary materials can be accessed at: http://www.mdpi.com/2075-1729/5/1/130/s1 .

\section{Conflicts of Interest}

The authors declare no conflict of interest. 


\section{References}

1. Varki, A. Essentials of Glycobiology, 2nd ed.; Cold Spring Harbor Laboratory Press: New York, NY, USA, 2009.

2. Sazuka, T.; Ohara, O. Towards a proteome project of cyanobacterium Synechocystis sp. strain PCC6803: Linking 130 protein spots with their respective genes. Electrophoresis 1997, 18, $1252-1258$.

3. Sazuka, T.; Yamaguchi, M.; Ohara, O. Cyano2Dbase updated: Linkage of 234 protein spots to corresponding genes through N-terminal microsequencing. Electrophoresis 1999, 20, 2160-2171.

4. Choi, J.S.; Kim, D.S.; Lee, J.; Kim, S.J.; Kim, S.I.; Kim, Y.H.; Hong, J.; Yoo, J.S.; Suh, K.H.; Park, Y.M. Proteome analysis of light-induced proteins in Synechocystis sp. PCC 6803: Identification of proteins separated by 2D-PAGE using N-terminal sequencing and MALDI-TOF MS. Mol. Cells 2000, 10, 705-711.

5. Wegener, K.M.; Singh, A.K.; Jacobs, J.M.; Elvitigala, T.; Welsh, E.A.; Keren, N.; Gritsenko, M.A.; Ghosh, B.K.; Camp, D.G., II; Smith, R.D.; et al. Global proteomics reveal an atypical strategy for carbon/nitrogen assimilation by a cyanobacterium under diverse environmental perturbations. Mol. Cell. Proteomics 2010, 9, 2678-2689.

6. Pandhal, J.; Ow, S.Y.; Wright, P.C.; Biggs, C.A. Comparative proteomics study of salt tolerance between a nonsequenced extremely halotolerant cyanobacterium and its mildly halotolerant relative using in vivo metabolic labeling and in vitro isobaric labeling. J. Proteome Res. 2009, 8, 818-828.

7. Pandhal, J.; Wright, P.C.; Biggs, C.A. Proteomics with a pinch of salt: A cyanobacterial perspective. Saline Syst. 2008, 4, doi:10.1186/1746-1448-4-1.

8. Rowland, J.G.; Simon, W.J.; Prakash, J.S.; Slabas, A.R. Proteomics reveals a role for the RNA helicase CrhR in the modulation of multiple metabolic pathways during cold acclimation of Synechocystis sp. PCC6803. J. Proteome Res. 2011, 10, 3674-3689.

9. Zhang, L.; Selão, T.T.; Pisareva, T.; Qian, J.; Sze, S.K.; Carlberg, I.; Norling, B. Deletion of Synechocystis sp. PCC 6803 leader peptidase LepB1 affects photosynthetic complexes and respiration. Mol. Cell. Proteomics 2013, 12, 1192-1203.

10. Li, T.; Yang, H.M.; Cui, S.X.; Suzuki, I.; Zhang, L.F.; Li, L.; Bo, T.T.; Wang, J.; Murata, N.; Huang, F. Proteomic study of the impact of hik33 mutation in Synechocystis sp. PCC 6803 under normal and salt stress conditions. J. Proteome Res. 2012, 11, 502-514.

11. Barrios-Llerena, M.E.; Reardon, K.F.; Wright, P.C. 2-DE proteomic analysis of the model cyanobacterium Anabaena variabilis. Electrophoresis 2007, 28, 1624-1632.

12. Gan, C.S.; Reardon, K.F.; Wright, P.C. Comparison of protein and peptide prefractionation methods for the shotgun proteomic analysis of Synechocystis sp. PCC 6803. Proteomics 2005, 5, 2468-2478.

13. Pereira, S.B.; Ow, S.Y.; Barrios-Llerena, M.E.; Wright, P.C.; Moradas-Ferreira, P.; Tamagnini, P. iTRAQ-based quantitative proteomic analysis of Gloeothece sp. PCC 6909: Comparison with its sheathless mutant and adaptations to nitrate deficiency and sulfur limitation. J. Proteomics 2011, $75,270-283$.

14. Ow, S.Y.; Noirel, J.; Cardona, T.; Taton, A.; Lindblad, P.; Stensjo, K.; Wright, P.C. Quantitative overview of $\mathrm{N}_{2}$ fixation in Nostoc punctiforme ATCC 29133 through cellular enrichments and iTRAQ shotgun proteomics. J. Proteome Res. 2009, 8, 187-198. 
15. Ow, S.Y.; Cardona, T.; Taton, A.; Magnuson, A.; Lindblad, P.; Stensjo, K.; Wright, P.C. Quantitative shotgun proteomics of enriched heterocysts from Nostoc sp. PCC 7120 using 8-plex isobaric peptide tags. J. Proteome Res. 2008, 7, 1615-1628.

16. Anderson, D.C.; Campbell, E.L.; Meeks, J.C. A soluble 3D LC/MS/MS proteome of the filamentous cyanobacterium Nostoc punctiforme. J. Proteome Res. 2006, 5, 3096-3104.

17. Aryal, U.K.; Callister, S.J.; McMahon, B.H.; McCue, L.A.; Brown, J.; Stockel, J.; Liberton, M.; Mishra, S.; Zhang, X.; Nicora, C.D.; et al. Proteomic profiles of five strains of oxygenic photosynthetic cyanobacteria of the genus Cyanothece. J. Proteome Res. 2014, 13, 3262-3276.

18. Huang, F.; Hedman, E.; Funk, C.; Kieselbach, T.; Schroder, W.P.; Norling, B. Isolation of outer membrane of Synechocystis sp. PCC 6803 and its proteomic characterization. Mol. Cell. Proteomics 2004, 3, 586-595.

19. Moslavac, S.; Bredemeier, R.; Mirus, O.; Granvogl, B.; Eichacker, L.A.; Schleiff, E. Proteomic analysis of the outer membrane of Anabaena sp. strain PCC 7120. J. Proteome Res. 2005, 4, 1330-1338.

20. Fulda, S.; Huang, F.; Nilsson, F.; Hagemann, M.; Norling, B. Proteomics of Synechocystis sp. strain PCC 6803. Identification of periplasmic proteins in cells grown at low and high salt concentrations. Eur. J. Biochem. 2000, 267, 5900-5907.

21. Zhang, L.F.; Yang, H.M.; Cui, S.X.; Hu, J.; Wang, J.; Kuang, T.Y.; Norling, B.; Huang, F. Proteomic analysis of plasma membranes of cyanobacterium Synechocystis sp. strain PCC 6803 in response to high pH stress. J. Proteome Res. 2009, 8, 2892-2902.

22. Huang, F.; Parmryd, I.; Nilsson, F.; Persson, A.L.; Pakrasi, H.B.; Andersson, B.; Norling, B. Proteomics of Synechocystis sp. strain PCC 6803: Identification of plasma membrane proteins. Mol. Cell. Proteomics 2002, 1, 956-966.

23. Simon, W.J.; Hall, J.J.; Suzuki, I.; Murata, N.; Slabas, A.R. Proteomic study of the soluble proteins from the unicellular cyanobacterium Synechocystis sp. PCC6803 using automated matrix-assisted laser desorption/ionization-time of flight peptide mass fingerprinting. Proteomics 2002, 2, 1735-1742.

24. Agarwal, R.; Matros, A.; Melzer, M.; Mock, H.P.; Sainis, J.K. Heterogeneity in thylakoid membrane proteome of Synechocystis 6803. J. Proteomics 2010, 73, 976-991.

25. Srivastava, R.; Pisareva, T.; Norling, B. Proteomic studies of the thylakoid membrane of Synechocystis sp. PCC 6803. Proteomics 2005, 5, 4905-4916.

26. Hahn, A.; Stevanovic, M.; Brouwer, E.; Bublak, D.; Tripp, J.; Schorge, T.; Karas, M.; Schleiff, E. Secretome analysis of Anabaena sp. PCC 7120 and the involvement of the TolC-homologue HgdD in protein secretion. Environ. Microbiol. 2014, doi:10.1111/1462-2920.12516.

27. Helm, R.D.; Potts, M. Extracellular matrix (ECM). In Ecology of Cyanobacteria II: Their Diversity in Space and Time; Whitton, B.A., Ed.; Springer: Berlin/Heidelberg, Germany, 2012; pp. 461-480.

28. Kehr, J.C.; Zilliges, Y.; Springer, A.; Disney, M.D.; Ratner, D.D.; Bouchier, C.; Seeberger, P.H.; de Marsac, N.T.; Dittmann, E. A mannan binding lectin is involved in cell-cell attachment in a toxic strain of Microcystis aeruginosa. Mol. Microbiol. 2006, 59, 893-906.

29. Sergeyenko, T.V.; Los, D.A. Identification of secreted proteins of the cyanobacterium Synechocystis sp. strain PCC 6803. FEMS Microbiol. Lett. 2000, 193, 213-216. 
30. Vilhauer, L.; Jervis, J.; Ray, W.K.; Helm, R.F. The exo-proteome and exo-metabolome of Nostoc punctiforme (cyanobacteria) in the presence and absence of nitrate. Arch. Microbiol. 2014, 196, 357-367.

31. Zilliges, Y.; Kehr, J.C.; Mikkat, S.; Bouchier, C.; de Marsac, N.T.; Borner, T.; Dittmann, E. An extracellular glycoprotein is implicated in cell-cell contacts in the toxic cyanobacterium Microcystis aeruginosa PCC 7806. J. Bacteriol. 2008, 190, 2871-2879.

32. Desvaux, M.; Hebraud, M.; Talon, R.; Henderson, I.R. Secretion and subcellular localizations of bacterial proteins: A semantic awareness issue. Trends Microbiol. 2009, 17, 139-145.

33. Rippka, R.; Deruelles, J.; Waterbury, J.B.; Herdman, M.; Stanier, R.Y. Generic assignments, strain histories and properties of pure cultures of cyanobacteria. J. Gen. Microbiol. 1979, 111, 1-61.

34. Oliveira, P.; Pinto, F.; Pacheco, C.C.; Mota, R.; Tamagnini, P. HesF, an exoprotein required for filament adhesion and aggregation in Anabaena sp. PCC 7120. Environ. Microbiol. 2014, doi:10.1111/1462-2920.12600.

35. Laemmli, U.K. Cleavage of structural proteins during the assembly of the head of bacteriophage T4. Nature 1970, 227, 680-685.

36. Shevchenko, A.; Wilm, M.; Vorm, O.; Mann, M. Mass spectrometric sequencing of proteins silver-stained polyacrylamide gels. Anal. Chem. 1996, 68, 850-858.

37. Gluck, F.; Hoogland, C.; Antinori, P.; Robin, X.; Nikitin, F.; Zufferey, A.; Pasquarello, C.; Fetaud, V.; Dayon, L.; Muller, M.; et al. EasyProt-An easy-to-use graphical platform for proteomics data analysis. J. Proteomics 2013, 79, 146-160.

38. Elias, J.E.; Gygi, S.P. Target-decoy search strategy for increased confidence in large-scale protein identifications by mass spectrometry. Nat. Methods 2007, 4, 207-214.

39. Yu, N.Y.; Wagner, J.R.; Laird, M.R.; Melli, G.; Rey, S.; Lo, R.; Dao, P.; Sahinalp, S.C.; Ester, M.; Foster, L.J.; et al. PSORTb 3.0: Improved protein subcellular localization prediction with refined localization subcategories and predictive capabilities for all prokaryotes. Bioinformatics 2010, 26, 1608-1615.

40. Lopes Pinto, F.; Erasmie, S.; Blikstad, C.; Lindblad, P.; Oliveira, P. FtsZ degradation in the cyanobacterium Anabaena sp. strain PCC 7120. J. Plant Physiol. 2011, 168, 1934-1942.

41. Pitcher, L.H.; Brennan, E.; Zilinskas, B.A. The antiozonant ethylenediurea does not act via superoxide dismutase induction in bean. Plant Physiol. 1992, 99, 1388-1392.

42. Hempel, S.L.; Buettner, G.R.; O’Malley, Y.Q.; Wessels, D.A.; Flaherty, D.M. Dihydrofluorescein diacetate is superior for detecting intracellular oxidants: Comparison with 2',7'-dichlorodihydrofluorescein diacetate, 5(and 6)-carboxy-2',7'-dichlorodihydrofluorescein diacetate, and dihydrorhodamine 123. Free Radic. Biol. Med. 1999, 27, 146-159.

43. Pereira, S.; Zille, A.; Micheletti, E.; Moradas-Ferreira, P.; De Philippis, R.; Tamagnini, P. Complexity of cyanobacterial exopolysaccharides: Composition, structures, inducing factors and putative genes involved in their biosynthesis and assembly. FEMS Microbiol. Rev. 2009, 33, 917-941.

44. Heidorn, T.; Camsund, D.; Huang, H.H.; Lindberg, P.; Oliveira, P.; Stensjo, K.; Lindblad, P. Synthetic biology in cyanobacteria engineering and analyzing novel functions. Methods Enzymol. 2011, 497, 539-579. 
45. Nanni, P.; Levander, F.; Roda, G.; Caponi, A.; James, P.; Roda, A. A label-free nano-liquid chromatography-mass spectrometry approach for quantitative serum peptidomics in Crohn's disease patients. J. Chromatogr. B Anal. Technol. Biomed. Life Sci. 2009, 877, 3127-3136.

46. Koropatkin, N.M.; Pakrasi, H.B.; Smith, T.J. Atomic structure of a nitrate-binding protein crucial for photosynthetic productivity. Proc. Natl. Acad. Sci. USA 2006, 103, 9820-9825.

47. Lopez-Igual, R.; Picossi, S.; Lopez-Garrido, J.; Flores, E.; Herrero, A. N and C control of ABC-type bicarbonate transporter $\mathrm{Cmp}$ and its LysR-type transcriptional regulator $\mathrm{CmpR}$ in a heterocyst-forming cyanobacterium, Anabaena sp. Environ. Microbiol. 2012, 14, 1035-1048.

48. Maeda, S.; Omata, T. Substrate-binding lipoprotein of the cyanobacterium Synechococcus sp. strain PCC 7942 involved in the transport of nitrate and nitrite. J. Biol. Chem. 1997, 272, 3036-3041.

49. Kellett, L.E.; Poole, D.M.; Ferreira, L.M.; Durrant, A.J.; Hazlewood, G.P.; Gilbert, H.J. Xylanase B and an arabinofuranosidase from Pseudomonas fluorescens subsp. cellulosa contain identical cellulose-binding domains and are encoded by adjacent genes. Biochem. J. 1990, 272, 369-376.

50. Meiss, G.; Gimadutdinow, O.; Haberland, B.; Pingoud, A. Mechanism of DNA cleavage by the DNA/RNA-non-specific Anabaena sp. PCC 7120 endonuclease NucA and its inhibition by NuiA. J. Mol. Biol. 2000, 297, 521-534.

51. Muro-Pastor, A.M.; Flores, E.; Herrero, A.; Wolk, C.P. Identification, genetic analysis and characterization of a sugar-non-specific nuclease from the cyanobacterium Anabaena sp. PCC 7120. Mol. Microbiol. 1992, 6, 3021-3030.

52. Ekman, M.; Picossi, S.; Campbell, E.L.; Meeks, J.C.; Flores, E. A Nostoc punctiforme sugar transporter necessary to establish a cyanobacterium-plant symbiosis. Plant Physiol. 2013, 161, 1984-1992.

53. Mastronunzio, J.E.; Huang, Y.; Benson, D.R. Diminished exoproteome of Frankia spp. in culture and symbiosis. Appl. Environ. Microbiol. 2009, 75, 6721-6728.

54. Osbourne, D.; Aruni, A.W.; Dou, Y.; Perry, C.; Boskovic, D.S.; Roy, F.; Fletcher, H.M. VimA-dependent modulation of the secretome in Porphyromonas gingivalis. Mol. Oral Microbiol. 2012, 27, 420-435.

55. Tjalsma, H. Feature-based reappraisal of the Bacillus subtilis exoproteome. Proteomics 2007, 7, 73-81.

56. Tjalsma, H.; Antelmann, H.; Jongbloed, J.D.; Braun, P.G.; Darmon, E.; Dorenbos, R.; Dubois, J.Y.; Westers, H.; Zanen, G.; Quax, W.J.; et al. Proteomics of protein secretion by Bacillus subtilis: Separating the "secrets" of the secretome. Microbiol. Mol. Biol. Rev. 2004, 68, 207-233.

57. Ziebandt, A.K.; Kusch, H.; Degner, M.; Jaglitz, S.; Sibbald, M.J.; Arends, J.P.; Chlebowicz, M.A.; Albrecht, D.; Pantucek, R.; Doskar, J.; et al. Proteomics uncovers extreme heterogeneity in the Staphylococcus aureus exoproteome due to genomic plasticity and variant gene regulation. Proteomics 2010, 10, 1634-1644.

58. Silva, W.M.; Seyffert, N.; Santos, A.V.; Castro, T.L.; Pacheco, L.G.; Santos, A.R.; Ciprandi, A.; Dorella, F.A.; Andrade, H.M.; Barh, D.; et al. Identification of 11 new exoproteins in Corynebacterium pseudotuberculosis by comparative analysis of the exoproteome. Microb. Pathog. 2013, 61-62, 37-42. 
59. Mashburn-Warren, L.M.; Whiteley, M. Special delivery: Vesicle trafficking in prokaryotes. Mol. Microbiol. 2006, 61, 839-846.

60. Kulp, A.; Kuehn, M.J. Biological functions and biogenesis of secreted bacterial outer membrane vesicles. Annu. Rev. Microbiol. 2010, 64, 163-184.

61. Biller, S.J.; Schubotz, F.; Roggensack, S.E.; Thompson, A.W.; Summons, R.E.; Chisholm, S.W. Bacterial vesicles in marine ecosystems. Science 2014, 343, 183-186.

62. Walda, C.; Stucken, K.; Dagan, T. Characterization of outer membrane vesicles in cyanobacteria. In Proceedings of the 9th European Workshop on the Molecular Biology of Cyanobacteria, Texel, The Netherlands, 7-11 September 2014; p. 91.

63. Raynaud, C.; Etienne, G.; Peyron, P.; Laneelle, M.A.; Daffe, M. Extracellular enzyme activities potentially involved in the pathogenicity of Mycobacterium tuberculosis. Microbiology 1998, 144, 577-587.

64. Smith, I. Mycobacterium tuberculosis pathogenesis and molecular determinants of virulence. Clin. Microbiol. Rev. 2003, 16, 463-496.

65. Gerlach, D.; Reichardt, W.; Vettermann, S. Extracellular superoxide dismutase from Streptococcus pyogenes type 12 strain is manganese-dependent. FEMS Microbiol. Lett. 1998, 160, 217-224.

66. Kaakoush, N.O.; Man, S.M.; Lamb, S.; Raftery, M.J.; Wilkins, M.R.; Kovach, Z.; Mitchell, H. The secretome of Campylobacter concisus. FEBS J. 2010, 277, 1606-1617.

67. Shirkey, B.; Kovarcik, D.P.; Wright, D.J.; Wilmoth, G.; Prickett, T.F.; Helm, R.F.; Gregory, E.M.; Potts, M. Active Fe-containing superoxide dismutase and abundant sodF mRNA in Nostoc commune (cyanobacteria) after years of desiccation. J. Bacteriol. 2000, 182, 189-197.

68. Regelsberger, G.; Obinger, C.; Zoder, R.; Altmann, F.; Peschek, G.A. Purification and characterization of a hydroperoxidase from the cyanobacterium Synechocystis PCC 6803: Identification of its gene by peptide mass mapping using matrix assisted laser desorption ionization time-of-flight mass spectrometry. FEMS Microbiol. Lett. 1999, 170, 1-12.

69. Tichy, M.; Vermaas, W. In vivo role of catalase-peroxidase in Synechocystis sp. strain PCC 6803. J Bacteriol. 1999, 181, 1875-1882.

70. Pascual, M.B.; Mata-Cabana, A.; Florencio, F.J.; Lindahl, M.; Cejudo, F.J. Overoxidation of 2-Cys peroxiredoxin in prokaryotes: Cyanobacterial 2-Cys peroxiredoxins sensitive to oxidative stress. J. Biol. Chem. 2010, 285, 34485-34492.

71. Halliwell, B. Are polyphenols antioxidants or pro-oxidants? What do we learn from cell culture and in vivo studies? Arch. Biochem. Biophys. 2008, 476, 107-112.

72. López, D.; Vlamakis, H.; Kolter, R. Biofilms. Cold Spring Harb. Perspect. Biol. 2010, 2, doi:10.1101/cshperspect.a000398.

73. Theoret, J.R.; Cooper, K.K.; Zekarias, B.; Roland, K.L.; Law, B.F.; Curtiss, R., III; Joens, L.A. The Campylobacter jejuni Dps homologue is important for in vitro biofilm formation and cecal colonization of poultry and may serve as a protective antigen for vaccination. Clin. Vaccine Immunol. 2012, 19, 1426-1431.

74. Enany, S.; Yoshida, Y.; Magdeldin, S.; Bo, X.; Zhang, Y.; Enany, M.; Yamamoto, T. Two dimensional electrophoresis of the exo-proteome produced from community acquired methicillin resistant Staphylococcus aureus belonging to clonal complex 80. Microbiol. Res. 2013, $168,504-511$. 
75. Kim, S.K.; Park, M.K.; Kim, S.H.; Oh, K.G.; Jung, K.H.; Hong, C.H.; Yoon, J.W.; Chai, Y.G. Identification of stringent response-related and potential serological proteins released from Bacillus

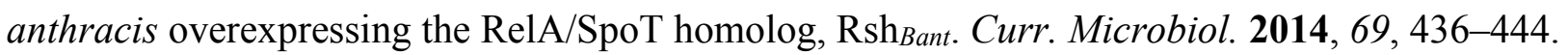

76. Avila-Calderon, E.D.; Lopez-Merino, A.; Jain, N.; Peralta, H.; Lopez-Villegas, E.O.; Sriranganathan, N.; Boyle, S.M.; Witonsky, S.; Contreras-Rodriguez, A. Characterization of outer membrane vesicles from Brucella melitensis and protection induced in mice. Clin. Dev. Immunol. 2012, 2012, doi:10.1155/2012/352493.

77. Christie-Oleza, J.A.; Pina-Villalonga, J.M.; Bosch, R.; Nogales, B.; Armengaud, J. Comparative proteogenomics of twelve Roseobacter exoproteomes reveals different adaptive strategies among these marine bacteria. Mol. Cell. Proteomics 2012, 11, doi:10.1074/mcp.M111.013110.

78. Pittman, M.S.; Robinson, H.C.; Poole, R.K. A bacterial glutathione transporter (Escherichia coli CydDC) exports reductant to the periplasm. J. Biol. Chem. 2005, 280, 32254-32261.

79. Kwon, S.O.; Gho, Y.S.; Lee, J.C.; Kim, S.I. Proteome analysis of outer membrane vesicles from a clinical Acinetobacter baumannii isolate. FEMS Microbiol. Lett. 2009, 297, 150-156.

80. Reed, B.; Chen, R. Biotechnological applications of bacterial protein secretion: From therapeutics to biofuel production. Res. Microbiol. 2013, 164, 675-682.

81. Lindblad, P.; Lindberg, P.; Oliveira, P.; Stensjo, K.; Heidorn, T. Design, engineering, and construction of photosynthetic microbial cell factories for renewable solar fuel production. Ambio 2012, 41, 163-168.

82. Ozturk, S.; Aslim, B.; Suludere, Z.; Tan, S. Metal removal of cyanobacterial exopolysaccharides by uronic acid content and monosaccharide composition. Carbohydr. Polym. 2014, 101, 265-271.

83. Haselkorn, R. Heterocyst differentiation and nitrogen fixation in cyanobacteria. In Associative and Endophytic Nitrogen-Fixing Bacteria and Cyanobacterial Associations; Elmrich, C., Newton, W.E., Eds.; Springer: Dordrecht, The Netherlands, 2007; Volume 5, pp. 233-255.

84. Burnat, M.; Herrero, A.; Flores, E. Compartmentalized cyanophycin metabolism in the diazotrophic filaments of a heterocyst-forming cyanobacterium. Proc. Natl. Acad. Sci. USA 2014, 111, 3823-3828.

85. Tamagnini, P.; Leitão, E.; Oliveira, P.; Ferreira, D.; Pinto, F.; Harris, D.J.; Heidorn, T.; Lindblad, P. Cyanobacterial hydrogenases: Diversity, regulation and applications. FEMS Microbiol. Rev. 2007, 31, 692-720.

86. Camsund, D.; Heidorn, T.; Lindblad, P. Design and analysis of LacI-repressed promoters and DNA-looping in a cyanobacterium. J. Biol. Eng. 2014, 8, doi:10.1186/1754-1611-8-4.

87. Huang, H.H.; Lindblad, P. Wide-dynamic-range promoters engineered for cyanobacteria. J. Biol. Eng. 2013, 7, doi:10.1186/1754-1611-7-10.

88. Chen, D.J.; Osterrieder, N.; Metzger, S.M.; Buckles, E.; Doody, A.M.; DeLisa, M.P.; Putnam, D. Delivery of foreign antigens by engineered outer membrane vesicle vaccines. Proc. Natl. Acad. Sci. USA 2010, 107, 3099-3104.

(C) 2015 by the authors; licensee MDPI, Basel, Switzerland. This article is an open access article distributed under the terms and conditions of the Creative Commons Attribution license (http://creativecommons.org/licenses/by/4.0/). 